\title{
Meaning-Preserving Translations of Non-classical Logics into Classical Logic: Between Pluralism and Monism
}

\author{
Gerhard Schurz ${ }^{1}$ (D)
}

Received: 3 October 2020 / Accepted: 31 May 2021/Published online: 6 September 2021

(C) The Author(s) 2021

\begin{abstract}
In order to prove the validity of logical rules, one has to assume these rules in the metalogic. However, rule-circular 'justifications' are demonstrably without epistemic value (sec. 1). Is a non-circular justification of a logical system possible? This question attains particular importance in view of lasting controversies about classical versus nonclassical logics. In this paper the question is answered positively, based on meaningpreserving translations between logical systems. It is demonstrated that major systems of non-classical logic, including multi-valued, paraconsistent, intuitionistic and quantum logics, can be translated into classical logic by introducing additional intensional operators into the language (sec. 2-5). Based on this result it is argued that classical logic is representationally optimal. In sec. 6 it is investigated whether non-classical logics can be likewise representationally optimal. The answer is predominantly negative but partially positive. Nevertheless the situation is not symmetric, because classical logic has important ceteris paribus advantages as a unifying metalogic.
\end{abstract}

Keywords Translations of non-classical into classical logics $\cdot$ Meaning-preserving translations $\cdot$ Representational optimality, logical pluralism

\section{Introduction: The Significance of Non-circular Justifications for Contemporary Philosophy of Logic}

The background of this paper is a foundation-theoretic epistemology whose class of 'basic' beliefs is minimalistic, consisting only of immediately evident analytical and introspective beliefs (cf. [59, 60]). In this framework the major epistemic load has to be carried by deductive, inductive or abductive reasoning.

Gerhard Schurz

schurz@hhu.de; http://www.philosophie.hhu.de/schurz

1 Düsseldorf Center for Logic and Philosophy of Science (DCLPS), Heinrich Heine University

Düsseldorf, Universitätsstraße 1, Geb. 24.52, 40225 Düsseldorf, Germany 
Therefore the 'higher order' justification of the reasonability or reliability of the rules governing these inferences acquires central importance. Many contemporary epistemologists consider the problem of higher order justification as unsolvable, because it leads into a circle or infinite regress. In epistemological movements such as coherentism and (partly) externalism it is argued that rulecircular justifications, in which the rule to be justified is employed in the justificatory argument, are a viable solution to this problem. ${ }^{1}$ However, it can be demonstrated that rule-circular justifications are epistemically worthless, because with such a justification both a rule and the opposite rule can be proved. For example, both the rule of induction and the rule of counterinduction (that infers the opposite of what induction infers) can be rulecircularly 'justified' as follows ([56], 46):

(1) Rule-circular justification of induction:

Premise: Past inductions have been successful.

Therefore, by rule of induction:

Future inductions will be successful.

\section{Rule-circular justification of counter-induction:}

Premise: Past counter-inductions have not been successful.

Therefore, by rule of counter-induction:

Future counter-inductions will be successful.

A similar situation arises when the semantic validity of logical rules is proved by employing these rules in the metalogic. To substantiate this claim let us introduce a bit of notation: In what follows, the indexed letter $\mathrm{L}_{\mathrm{i}}$ varies over systems of propositional object logics and $\mathscr{D}_{\mathrm{i}}$ designates their language (identified with the set of their well-formed formulas). $\mathrm{ML}_{\mathrm{i}}$ denotes a metalogic in which we can express truth assertions about $\mathrm{L}_{\mathrm{i}}$-sentences. It is sufficient for our purpose to represent $\mathrm{ML}_{\mathrm{i}}$ as a modal extension of $\mathrm{L}_{\mathrm{i}}$, obtained by adding an intensional truth operator $\mathrm{T}$ (a generalized modal operator) to $\mathrm{L}_{\mathrm{i}}$ for which the correspondence (or 'redundancy') axiom (C): TA $\leftrightarrow \mathrm{A}$ holds. ${ }^{2} \mathrm{~L}_{2}$ denotes the classical (bivalent) propositional logic, with $\mathscr{D}_{2}$ containing $\neg, \wedge, \vee$ as Boolean connectives and $\rightarrow, \leftrightarrow$ for the material implication and equivalence. $\Gamma \mid==_{\mathrm{L} 2}$ A stands for the corresponding inference relation (defined via truth preservation). Moreover, we use $\mathrm{p}_{1}, \mathrm{p}_{2}, \ldots, \mathrm{q}, \mathrm{r} \ldots$ as (propositional) variables, A, $\mathrm{B}, \ldots$ as schematic letters for are arbitrary formulas (sentences); $\Gamma, \Delta, \ldots$ designate arbitrary sets of formulas.

Already Haack [28] pointed out in her example of "Modus morons" that with help of rule-circular arguments rather weird rules could be 'proved' as valid. We illustrate this point by the following example of two circular metalogical 'proofs' differing only in their final lines: the left one 'proving' the validity of Modus Ponens, MP, and the right one 'proving' the validity of the opposite rule, called Modus Nonsense, MN: " $\mathrm{p}, \mathrm{p} \rightarrow \mathrm{q}$ / $\neg$ "” (truth tables are assumed to be the classical ones):

\footnotetext{
${ }^{1}$ Among others, the following philosophers supported rule-circular justifications. Coherentists: Sellars [62], Lehrer [41] and the early BonJour [7]. Externalists: Goldman [25], van Cleve [68] and Greco [27]. Philosophers of science: Papineau [48], Lipton [43] and Psillos [53].

${ }^{2}$ For truth as a sentence operator the axiom (C) cannot produce antinomies. The modal logic for (C) is semantically characterized by the class of worlds seeing exactly themselves.
} 
(2) Rule-circular 'proofs' of the validity of Modus ponens and Modus nonsense:

\begin{tabular}{|c|c|c|c|}
\hline \multicolumn{2}{|c|}{ 1. $\mathrm{T}(\mathrm{p} \rightarrow \mathrm{q})$} & & Premise \\
\hline & 2. Tp & & Premise \\
\hline & 3. $\mathrm{Tp} \rightarrow \mathrm{Tq}$ & & From 1 by $\rightarrow$ 's truth table \\
\hline 4. $\mathrm{Tq}$ & From 2, 3 and MP & $4^{*} \cdot \neg \mathrm{Tq}$ & From 2, 3 and $\mathrm{MN}$ \\
\hline & & $5^{*} . \mathrm{T} \neg \mathrm{q}$ & From $4 *$ by $\neg$ 's truth table \\
\hline
\end{tabular}

In conclusion, rule-circular 'justifications' may be semantically illuminating, but they do not provide real justification. Rather, the validity or invalidity of these rules is assumed as basic 'knowledge' that is simply accepted and has no further positive justification. ${ }^{3}$ Technically this basic knowledge can be explicated either semantically, in propositional logic by means of truth tables, or syntactically by means of an axiomatic system. In our example, we 'know' that only step 4 but not step $4^{*}$ is correct, because only the rule MP but not the rule MN is validated by the classical truth tables, that are assumed as basic.

If systems of logic cannot be justified by means of logical demonstration, what other possibilities of justifying them are there? Prima facie, the purpose of logics is to explicate valid inference (cf. Beall and Restall's Generalized Tarski Thesis; [4], 29), but the rules of valid inference depend on the basic logical operators. To a certain extent, the basic logical operators can be justified in a Kantian 'transcendental' sense, as a presupposition of the possibility of cognition at all. For example, the possibility of a true description of a manifold presupposes the operation of conjunction; expressing that a certain description is false presupposes the operation of negation; and similar arguments can be given for disjunction and implication. However, these a priori reasons do not determine the precise logical meaning of these operators; they constitute necessary conditions, but are too weak for a justification of a system of logic. The so-called classical logic is characterized by an additional semantic principle, the principle of bivalence: every statement $\mathrm{p}$ that is expressed in a semantically complete (non-indexical) way is either true or false. Thus, p cannot be 'undetermined', i.e. neither true nor false (the principle of excluded middle), nor can $\mathrm{p}$ be 'dialethic', i.e. both true and false (the principle of non-contradiction). Note that the principle of bivalence is not meant in an epistemic but in an ontological way. Ultimately this principle expresses the determinateness of reality: if " $p$ " is a semantically complete (non-indexical) sentence, then either $\mathrm{p}$ or not $\mathrm{p}$ must obtain.

Most non-classical logics reject the principle of two-valuedness, but in different ways and for different reasons. For example, Lukasiewicz' three-valued logic [44] originated from the thesis that there are sentences whose truth-value is objectively undetermined, with the consequence that the classical law of the excluded middle $(\mathrm{p} \vee \neg \mathrm{p})$ becomes invalid. Brouwer's intuitionistic logic [9] originated in the domain of mathematics and consisted in the replacement of the Platonist notion of mathematical truth by the concept of constructive mathematical verification, with the consequence

\footnotetext{
${ }^{3}$ In the sense of an inference from further reasons. Weaker forms of justifications for logical principles are possible, for example epistemic entitlement in the sense of Wright [74]. My argument from representational optimality developed in this paper is itself a weaker form of (internalist) justification.
} 
that for intuitionistic logic the classical law of double negation $(\neg p \rightarrow p)$ becomes invalid. Paraconsistent logic was motivated by the attempt to avoid the irrelevant inference of 'explosion' ( $\mathrm{p} \wedge \neg \mathrm{p} / \mathrm{q}$ ) by assuming the possibility of dialethic statements that are both true and false [51]. Still different is the motivation of quantum logic, attempting to represent the possibility of superposed quantum states by a non-classical disjunction that violates the expansion direction of distribution, $\mathrm{p} \wedge(\mathrm{q} \vee \mathrm{r}) \rightarrow(\mathrm{p} \wedge \mathrm{q}) \vee(\mathrm{p} \wedge \mathrm{r})$. For all these non-classical logics there have been lasting philosophical controversies about whether their objectives can be equally or even better realized by measures within classical logic. Let us avoid taking sides in these controversies, but consider the epistemological consequences of this situation. For a foundation-theoretic epistemology aiming at objective justification, these consequences are highly problematic. The key problem is this: Assessing the adequacy and the relative merits of a logic requires external standards, but apparently there are no such external standards, since every rational argument and even every description of evidence presupposes some kind of logic.

In contemporary philosophy of logic the view of logical anti-exceptionalism has been developed, as an opposition to the traditional logical apriorism. Defenders of this view (e.g., $[10,32]$ ) argue that logics are not 'exceptional' compared to the empirical sciences. More precisely, they argue that (a) it is false that the laws of logic have an exceptional apriori status, as it is traditionally assumed (for contemporary defenses of the apriori view cf. $[17,20])$. Rather (b) the laws of logic can be supported and revised according to empirical facts, similarly as has been the case for physical geometries [54]. In our view, thesis (a) is right, but thesis (b) is not tenable. The situation in logic is very different from the case of geometry. The justification of different systems of physical geometry (say Euclidean versus non-Euclidean) is based on independent systems of logico-mathematical description that do not presuppose a particular geometry. But every description of evidence for or against a given logic L presupposes a metalogic for describing this evidence and drawing conclusions from it about the status of $\mathrm{L}$ (cf. $[63,73]){ }^{4}$

There are also good reasons to accept a metalogic that is at least as strong as the object-logics one accepts. First, as Woods [73] has pointed out, if ML is weaker than L, then a purported conflict between a piece of evidence e and a rule $\mathrm{R}$ of $\mathrm{L}$ could simply be removed by removing the inference from $\mathrm{R}$ to $\neg \mathrm{e}$ in ML. Second, as Bremer [8] has shown, the common core logic of competing logics $\mathrm{L}_{1}, \mathrm{~L}_{2}(\ldots)$ is too weak as a framework for comparing those logics (cf. [63], 9). These considerations fit the common (though not ubiquitous) practice to use the strongest logic, namely classical logic, for the philosophical evaluation of non-classical logics. Typically the evidence for or against a non-classical logic is also described within classical metalogic, which is self-undermining in a sense.

On the other hand, as we have seen, for every 'logical' rule, no matter how bizarre, it is possible to adopt a suitably strong metalogic that permits a rule-circular 'proof' of the rule's validity. In conclusion, a non-circular strategy of justifying a system of logic is not in sight. All this seems to speak in favor of the exceptional status of logic as irreducibly basic. In combination with the plurality of competing logical systems, this

\footnotetext{
${ }^{4}$ Besides experiential facts, a further sort of evidence used by anti-exceptionalists are intuitions about validity. Intuition-based evidence has been criticized as subjective and unreliable (cf. [33, 61]).
} 
exceptional feature of logic seems to undermine the possibility of foundation-oriented epistemology. There are two threats emerging from this situation. First, there is the threat of relativism: It appears to be largely a subjective matter which logic one chooses, based on intuition or 'cognitive taste', but not upon objective reason. The threat of relativism would not be so bad if the choice of a logic were largely a matter of convention, like the choice of a conventional terminology. But the opposite appears to be the case: logic seems to constitute the innermost core of our belief system, determining all other parts. This brings us to the second threat - that of incommensurability: Proponents of different logics appear to be in a fundamental disagreement (about the logic one should use) that cannot be resolved by rational argumentation, nor even be formulated in a neutral way, because every formulation presupposes the adoption of a logic. ${ }^{5}$

\section{Optimality Justifications Based on Translations between Logics: Escape from Incommensurability and Relativism?}

Theoretically the problem of incommensurability appears to be even worse than that of relativism, as it seems to prevent a rational discourse between proponents of alternative logics. This theoretical diagnosis stands in remarkable contrast to the practice of logicians: proponents of different logics have no problem understanding each other, but exchange rational arguments all the time. How is this possible? The answer lies in hidden translation possibilities between non-classical and classical logics.

The study of translations methods between different logics has become an area of increasing research in contemporary logic [12]. The possibility of a particular kind of translations, namely meaning-preserving translations, constitutes one of the two major ideas underlying the present paper. Meaning-preserving translations between different systems of logic remove the threat of incommensurability, but not yet the threat of relativism, because they don't answer the question of how one can justify the choice of a logic in a non-circular way. The second idea of this paper is to answer this question by the method of optimality justifications.

The method of optimality justifications has been developed as an approach to the problem of induction, or Hume's problem [58,60]. An optimality justification does not attempt to demonstrate that a given epistemic method is strictly or probabilistically reliable, in the sense of leading to the truth in all or most cases. It pursues a more modest goal, namely to demonstrate that a given method is optimal in regard to a given epistemic goal, among all competing methods that are cognitively accessible to the given epistemic agent. It can be proved that in all possible worlds a certain method of meta-induction is predictively optimal in the long run, among all prediction methods that are accessible to the forecaster. ${ }^{6}$

In this paper the method of optimality justifications is applied to the domain of logic, focusing on propositional logic and its modal extensions. Optimality

\footnotetext{
5 The problem of 'incommensurability' was introduced by Kuhn [40] for the rational comparison of competing paradigms in science.

${ }^{6}$ More information in Schurz [60], Henderson [30], Sterkenburg [66], Feldbacher [19].
} 
justifications are relative to a given epistemic goal. In the case of induction, this goal is predictive success. What could the epistemic goal of logic be? In contemporary philosophical logic one often discusses goals such as intuitive naturalness, usefulness in certain domains, or agreement with assumed metaphysical positions. The problem with these goals is that they are too subjective and context-dependent to enable a robust objective optimality justification. For example, Priest [51], Williamson [71] as well as Bueno [10] and Hjortland [32] are anti-exceptionalists, but they draw opposite inferences about the preferred logic: Williamson prefers classical logic, Priest argues for paraconsistent logic, while Hjortland and Bueno opt for a version of logical pluralism. ${ }^{7}$ For a robust epistemic justification we need a more general epistemic goal, indeed a most general one, since logic is the most general level of description. The goal we propose for this purpose is power of linguistic representation, in short: representational power. Searching for optimality in regard to this goal is possible by applying meaning-preserving translations between different systems of logic.

In the next sections (3-5) it will be demonstrated that the most well-known systems of non-classical logics can be translated into classical logic. Our technique of achieving a meaning-preserving translation will consist in extending the language of classical logics by intensional operators who reflect the non-classical structure inside of their scope but behave classically outside of their scope. Based on this result it is argued that classical logic is representationally optimal: by using classical logic one can only win but not loose, because if a non-classical logic turns out to have advantages for certain purposes, it can be translated into classical logic. However, optimality doesn't imply dominance, but is compatible with a plurality of equally optimal logics. In sec. 6 it will be investigated whether non-classical logics can be likewise representationally optimal. The answer is predominantly negative but partially positive. Nevertheless the situation is not symmetric, because arguably classical logic has important ceteris paribus advantages in its role as a unifying metalogic.

\section{Translation of Many-Valued Logics}

\subsection{Translation of Lukasiewicz' Three-Valued Logic into Classical Logic}

In this section we develop the translation approach in application to Lukasiewicz' three-valued (propositional) logic $\mathrm{L}_{3}$ with the truth-values true $(\mathrm{t})$, false (f) and undetermined (u). Let us assume that the sentence "there is exactly one electron" is indeed neither true nor false but undetermined. Then, despite the assumed indeterminacy of this sentence, the statement that the sentence is undetermined is itself two-valued, either true or false, and certainly not undetermined. More generally, even in the trivalent logical framework, all

\footnotetext{
${ }^{7}$ Different notions of logical pluralism have been developed, e.g. local pluralism versus global pluralism ([31], $356 \mathrm{f}$.) and contextual pluralism [11]. Bueno's pluralism is contextualist and localist (different logics can be adequate for different domains and purposes).
} 
statements asserting the truth, indeterminateness or falsity of a certain statement are bivalent - since assuming a trivalent semantic assignment just means that these statements are bivalent. If we manage to translate all statements of the three-valued framework into combinations of bivalent statements of this sort, we have found a translation function. ${ }^{8}$

Let us carry out this translation in a precise way. The language $\mathrm{L}_{3}$ has four basic truth-functional connectives $\neg, \vee, \wedge$ and $\rightarrow$, where the three-valued conditional $\rightarrow$ is not definable in terms of the other three connectives. As usual one assumes a linear ordering among the truth-values of a (finite) multi-valued logic; in the case of $\mathrm{L}_{3}$ the ordering is $\mathrm{f}<\mathrm{u}<\mathrm{t}$; or represented as ranks: $-1,0,+1$. Based on this ordering, Lukasiewicz' three-valued truth-tables for the four connectives are described as follows: the truth value of $\neg \mathrm{p}$ is the inverse of $\mathrm{p}$ 's truth value, that of $\mathrm{p} \wedge \mathrm{q}$ is the minimum and that of $p \vee q$ the maximum of the truth values of $p$ and $q$. Finally, $p \rightarrow q$ 's truth value equals $t / u / f$ if the rank difference between q's truth value and $p$ 's truth value is not smaller than $0 /-1 /-2$, respectively.

\begin{tabular}{|c|c|c|c|c|c|c|}
\hline \multicolumn{2}{|c|}{$\mathrm{p}_{\mid} \neg \mathrm{p}$} & $\mathrm{p}$ & $\mathrm{q}$ & $\mathrm{p} \wedge \mathrm{q}$ & $p \vee q$ & $\mathrm{p} \rightarrow \mathrm{q}$ \\
\hline $\mathrm{t}$ & $\mathrm{f}$ & $\mathrm{t}$ & $\mathrm{t}$ & $\mathrm{t}$ & $\mathrm{t}$ & $\mathrm{t}$ \\
\hline $\mathrm{u}$ & $\mathrm{u}$ & $\mathrm{t}$ & $\mathrm{u}$ & $\mathrm{u}$ & $\mathrm{t}$ & $\mathrm{u}$ \\
\hline $\mathrm{f}$ & $\mathrm{t}$ & $\mathrm{t}$ & $\mathrm{f}$ & $\mathrm{f}$ & $\mathrm{t}$ & f \\
\hline & & $\mathrm{u}$ & $\mathrm{t}$ & $\mathrm{u}$ & $\mathrm{t}$ & $\mathrm{t}$ \\
\hline & & $\mathrm{u}$ & $\mathrm{u}$ & $\mathrm{u}$ & $\mathrm{u}$ & $\mathrm{t}$ \\
\hline & & $\mathrm{u}$ & f & $\mathrm{f}$ & $\mathrm{u}$ & $\mathrm{u}$ \\
\hline & & $\mathrm{f}$ & $\mathrm{t}$ & $\mathrm{f}$ & $\mathrm{t}$ & $\mathrm{t}$ \\
\hline & & $\mathrm{f}$ & $\mathrm{u}$ & $\mathrm{f}$ & $\mathrm{u}$ & $\mathrm{t}$ \\
\hline & & $\mathrm{f}$ & $\mathrm{f}$ & $\mathrm{f}$ & $\mathrm{f}$ & $\mathrm{t}$ \\
\hline
\end{tabular}

The notion of logical truth and validity in $\mathrm{L}_{3}$ is defined analogously as in bivalent logics. Let $\wp$ be the denumerable set of propositional variables, and $\mathrm{val}_{3}$ : $\wp \rightarrow\{\mathrm{t}, \mathrm{u}, \mathrm{f}\}$ range over trivalent truth-valuations of the variables, recursively extended to arbitrary complex $\mathscr{L}_{3}$-formulas via the above truth tables. Then an $\mathscr{B}_{3}$-formula $\mathrm{A}$ is logically true in $\mathrm{L}_{3}$, in short $\mid==_{3} \mathrm{~A}$ iff $\mathrm{val}_{3}(\mathrm{~A})=\mathrm{t}$ for all (possible) trivalent valuations, and A follows from a formula set $\Gamma$ in $\mathrm{L}_{3}$, in short $\Gamma \mid=={ }_{3} \mathrm{~A}$, iff all trivalent valuations making all formulas in $\Gamma$ true make $\mathrm{A}$ true. Here are some examples:

Some theorems of $L_{3}: \mathrm{p} \rightarrow(\mathrm{q} \rightarrow \mathrm{p}), \quad(\neg \mathrm{q} \rightarrow \neg \mathrm{p}) \leftrightarrow(\mathrm{p} \rightarrow \mathrm{q}), \quad(\mathrm{p} \vee \mathrm{q}) \leftrightarrow((\mathrm{p} \rightarrow \mathrm{q}) \rightarrow \mathrm{q})$.

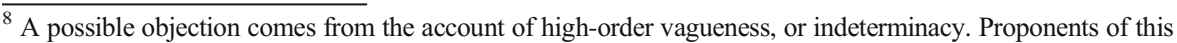
position argue that the truth-value statements $\mathrm{Tp}, \mathrm{Up}$ and $\mathrm{Fp}$ - short for "proposition $\mathrm{p}$ is true, undetermined or false, respectively" - may themselves be true, undetermined or false. A possible defeat of this objection goes as follows. There are two possibilities ([64], sec. $1+4)$ : Either (i) one stops the vagueness-iteration at some finite level $\mathrm{k}$, or (ii) the iteration goes on forever. In case (i), the truth-values of degree $\mathrm{k}(\mathrm{X}(\mathrm{p})$ for $\mathrm{X} \in$ $\{\mathrm{T}, \mathrm{U}, \mathrm{F}\}^{\mathrm{k}}$ ) are bivalent. In case (ii) one usually assumes an assignment of real numbers; then the statements of the form "the truth-degree of $p$ is $r$ " $(T(p)=r)$ are bivalent. Thus, there seems to be always an ultimate level of description at which descriptions are bivalent.
} 


\section{Some non-theorems of $L_{3}: \mathrm{p} \vee \neg \mathrm{p}, \quad \neg(\mathrm{p} \wedge \neg \mathrm{p}), \quad(\mathrm{p} \vee \mathrm{q}) \leftrightarrow(\neg \mathrm{p} \rightarrow \mathrm{q})$.}

Conditional proof $\Gamma, \mathrm{A}|==\mathrm{B} / \mathrm{\Gamma}|==\mathrm{A} \rightarrow \mathrm{B}$ fails for $\mathrm{L}_{3}$, because in $\mathrm{L}_{3}$ the logical truth of $\mathrm{A} \rightarrow \mathrm{B}$ is stronger than the validity of $\mathrm{A} / \mathrm{B}$ : while the latter implies merely that whenever $\mathrm{A}$ is true, $\mathrm{B}$ is true, the former implies in addition that when $\mathrm{A}$ is undetermined, $B$ is undetermined or true. For example, $p \wedge \neg p \mid==_{3}$ q but $\mid=/=_{3}(p \wedge \neg p) \rightarrow q$.

Our translation is based on the expansion of $\mathscr{C}_{2}$ by three operators T, $\mathrm{U}$ and $\mathrm{F}$ that express the truth values of being true, undetermined, and false in three-valued logic. If $\mathrm{p}$ is a sentence of the three-valued logic, the sentences $T(p), U(p)$ and $F(p)$ are bivalent and obey the following truth table:

\begin{tabular}{c|ccc}
$\mathrm{p}$ & $\mathrm{T}(\mathrm{p})$ & $\mathrm{U}(\mathrm{p})$ & $\mathrm{F}(\mathrm{p})$ \\
\hline $\mathrm{t}$ & $\mathrm{t}$ & $\mathrm{f}$ & $\mathrm{f}$ \\
$\mathrm{u}$ & $\mathrm{f}$ & $\mathrm{t}$ & $\mathrm{f}$ \\
$\mathrm{f}$ & $\mathrm{f}$ & $\mathrm{f}$ & $\mathrm{t}$
\end{tabular}

We don't need to introduce these operators in $\mathscr{D}_{3}$, because they are definable in $\mathrm{L}_{3}$ as follows:

$$
\begin{aligned}
& \mathrm{U}(\mathrm{A})={ }_{\operatorname{def}}(\mathrm{A} \vee \neg \mathrm{A}) \rightarrow(\mathrm{A} \wedge \neg \mathrm{A}), \\
& \mathrm{T}(\mathrm{A})={ }_{\operatorname{def}} \mathrm{A} \wedge \neg \mathrm{U}(\mathrm{A}), \text { and } \\
& \mathrm{F}(\mathrm{A})={ }_{\operatorname{def}} \neg \mathrm{A} \wedge \neg \mathrm{U}(\mathrm{A}) .
\end{aligned}
$$

It is easy to check that the truth-functions of these formulas in $\mathrm{L}_{3}$ coincide with the above truth tables for T, U and F.

By adding the Lukasiewicz-operators T, U, F to the classical language $\mathscr{L}_{2}$ we obtain the extended classical language $\mathrm{L}_{2 . \mathrm{Luk}}$ whose formulas are still evaluated bivalently and whose basic logical laws are still the classical laws of $\mathrm{L}_{2}$. Within $\mathrm{L}_{2}$ the operators $\mathrm{T}, \mathrm{U}$ and $\mathrm{F}$ figure as intensional (non-bivalently-truth-functional) operators, similar to the operators of modal logic. Based on the truth tables of these three operators, every semantic rule of three-valued logic can be translated into a set of corresponding axioms formulated in the extended language of classical logic as follows:

$$
\begin{array}{rrr}
\text {-For the negation: } & \mathrm{T}(\neg \mathrm{A}) \leftrightarrow \mathrm{F}(\mathrm{A}) \quad \mathrm{U}(\neg \mathrm{A}) \leftrightarrow \mathrm{U}(\mathrm{A}) \quad \mathrm{F}(\neg \mathrm{A}) \leftrightarrow \mathrm{T}(\mathrm{A}) \\
\text {-For the conjunction : } & \begin{array}{r}
\mathrm{T}(\mathrm{A} \wedge \mathrm{B}) \leftrightarrow \mathrm{T}(\mathrm{A}) \wedge \mathrm{T}(\mathrm{B}) \quad \mathrm{F}(\mathrm{A} \wedge \mathrm{B}) \leftrightarrow \mathrm{F}(\mathrm{A}) \vee \mathrm{F}(\mathrm{B}) \\
\mathrm{U}(\mathrm{A} \wedge \mathrm{B}) \leftrightarrow(\mathrm{U}(\mathrm{A}) \wedge \neg \mathrm{F}(\mathrm{B})) \vee(\mathrm{U}(\mathrm{B}) \wedge \neg \mathrm{F}(\mathrm{A}))
\end{array} \\
\text {-For the disjunction : } \begin{array}{r}
\mathrm{T}(\mathrm{A} \vee \mathrm{B}) \leftrightarrow \mathrm{T}(\mathrm{A}) \vee \mathrm{T}(\mathrm{B}) \quad \mathrm{F}(\mathrm{A} \vee \mathrm{B}) \leftrightarrow \mathrm{F}(\mathrm{A}) \wedge \mathrm{F}(\mathrm{B}) \\
\mathrm{U}(\mathrm{A} \vee \mathrm{B}) \leftrightarrow(\mathrm{U}(\mathrm{A}) \wedge \neg \mathrm{T}(\mathrm{B})) \vee(\mathrm{U}(\mathrm{B}) \wedge \neg \mathrm{T}(\mathrm{A})
\end{array}
\end{array}
$$


-For the implication: $\quad \mathrm{T}(\mathrm{A} \rightarrow \mathrm{B}) \leftrightarrow \mathrm{F}(\mathrm{A}) \vee(\mathrm{U}(\mathrm{A}) \wedge \neg \mathrm{F}(\mathrm{B})) \vee(\mathrm{T}(\mathrm{A}) \wedge \mathrm{T}(\mathrm{B}))$

$$
\begin{gathered}
\mathrm{U}(\mathrm{A} \rightarrow \mathrm{B}) \leftrightarrow(\mathrm{T}(\mathrm{A}) \wedge \mathrm{U}(\mathrm{B})) \vee((\mathrm{U}(\mathrm{A}) \wedge \mathrm{F}(\mathrm{B})) \\
\mathrm{F}(\mathrm{A} \rightarrow \mathrm{B}) \leftrightarrow \mathrm{T}(\mathrm{A}) \wedge \mathrm{F}(\mathrm{B})
\end{gathered}
$$

- Finally we add the trivalent truth-value axiom: $T(A) \dot{v} U(A) \dot{v} F(A)$ ("ن்" for exclusive disjunction, defined as usual).

The set of these axiom schemata forms the axiom system $\mathrm{Ax}_{\mathrm{Luk}}$ of Lukasiewicz' logic in the extended language of classical logic $\mathscr{D}_{2 . \text { Luk }}$.

We now turn to our proposed method of translating $\mathscr{D}_{3}$-assertions into $\mathscr{L}_{2}$-assertions. Our method is based on the truth view of assertion: asserting a sentence A means to assert that $\mathrm{A}$ is true (more on this in sec. 3.2.1). Thus our translation function " $\tau_{3} \rightarrow 2$ " (from $\mathscr{L}_{3}$ into $\mathscr{L}_{2}$ ) is this:

(3) For all $\mathrm{A} \in \mathscr{L}_{3}: \tau_{3 \rightarrow 2}(\mathrm{~A})=\mathrm{T}(\mathrm{A})$.

Note that the translation based on the assertion view is not recursive but holistic: it translates every complex $\mathscr{D}_{3}$-assertion at once into a statement of $\mathscr{L}_{2 \text {.Luk }}$. By applying the axioms in $\mathrm{Ax}_{\mathrm{Luk}}$ we can then transform every sentence of $\mathscr{C}_{2 \text {.Luk }}$ into a truthfunctional combination of modalized variables $\left(\mathrm{Tp}_{\mathrm{i}}, \mathrm{Up}_{\mathrm{i}}\right.$ or $\left.\mathrm{Fp}_{\mathrm{i}}\right)$ and thus find out what the translation means for the truth-value of the modalized variables of the sentence.

Some examples of translations and their equivalent transformations ("=" for identity, “ $\leftrightarrow$ ” for material $\mathrm{L}_{2}$-equivalence given $\mathrm{Ax}_{\mathrm{Luk}}$, " $\tau$ " short for " $\tau_{3 \rightarrow 2}$ "):

$$
\begin{aligned}
\tau(\mathrm{p}) & =\mathrm{T}(\mathrm{p}), \tau(\neg \mathrm{p})=\mathrm{T}(\neg \mathrm{p}) \leftrightarrow \mathrm{F}(\mathrm{p}), \tau(\mathrm{p} \vee \neg \mathrm{p})=\mathrm{T}(\mathrm{p} \vee \neg \mathrm{p}) \leftrightarrow \mathrm{Tp} \vee F \mathrm{p}, \tau(\mathrm{p} \wedge \neg \mathrm{p}) \\
& =\mathrm{T}(\mathrm{p} \wedge \neg \mathrm{p}) \leftrightarrow \mathrm{T} p \wedge \mathrm{Fp}, \tau(\mathrm{p} \rightarrow \mathrm{q})=\mathrm{T}(\mathrm{p} \rightarrow \mathrm{q}) \leftrightarrow \mathrm{Fp} \vee(\mathrm{Up} \wedge(\mathrm{Uq} \vee T \mathrm{q})) \vee(T \mathrm{p} \wedge \mathrm{Tq})
\end{aligned}
$$

Note that we use the same logical symbols for the two-valued and the three-valued propositional connectives (e.g., both " $\rightarrow$ " for two-valued and three-valued implication). This is not a problem, because whenever we translate an $\mathscr{L}_{3}$-formula into $\mathscr{L}_{2}$, the threevalued connectives are hedged in the scope of the intensional truth value operators $\mathrm{T}, \mathrm{U}$ and $\mathrm{F}$. When we bring them out of their scope by applying the equivalences of $A x_{\mathrm{Luk}}$, the three-valued connectives are transformed into the two-valued connectives of $\mathrm{L}_{2}$.

We now show that the translation $\tau_{3 \rightarrow 2}$ preserves meaning of modalized formulas and $\mathrm{L}_{3}$-logical truth (or validity) in a precise sense. For this purpose, we introduce some further terminology. In what follows, $\mathrm{O}_{\mathrm{i}}$ ranges over the three trivalent truth-value operators, $T, U$ and $F$. Let $P(A)=\left\{p_{1}, \ldots, p_{n}\right\}$ be the set of variables occurring in sentence A. We speak of the " $p_{i}$ " as "unmodalized variables" and of the statements " $\mathrm{O}_{\mathrm{i}} \mathrm{p}_{\mathrm{j}}$ " as the "modalized" variables. For $\wp$ a set of unmodalized variables, $\mathrm{O} \wp=U_{\mathrm{p} \in \wp}\{\mathrm{Tp}, \mathrm{Up}, \mathrm{Fp}\}$ denotes the corresponding set of modalized variables. If $\wp$ is the (denumerable) set of unmodalized variables common to $\mathscr{L}_{3}$ and $\mathscr{L}_{2 . \text { Luk }}$, then 
following from the intensional nature of the operators $\mathrm{O}_{\mathrm{i}}$, bivalent truth-valuations over $\mathscr{L}_{2 . \text { Luk }}$ are defined over the set of elementary formulas $\wp \cup \mathrm{O} \wp$. Let $\operatorname{Val}_{3}(\wp)$ be the set of all trivalent valuations over $\wp$ and $\mathrm{Val}_{3}$ be the set of (recursively extended) trivalent valuations over sentences of $\mathscr{B}_{3}$. Moreover, let $\mathrm{Val}_{2 . \mathrm{Luk}}(\mathrm{O} \wp)$ be the set of all bivalent valuations over $\mathrm{O} \wp$ satisfying the axiom $\mathrm{T}(\mathrm{A}) \dot{\mathrm{V}} \mathrm{U}(\mathrm{A}) \dot{\mathrm{V}} \mathrm{F}(\mathrm{A})$. Moreover, let $\mathscr{D}_{2 . \mathrm{Luk}, \tau}$ be the set of $\mathscr{L}_{2 . \mathrm{Luk}}$-formulas that are $\mathrm{Ax}_{\mathrm{Luk}}$-equivalent with translations of $\mathscr{L}_{3}$-formulas, and let $\mathrm{Val}_{2 . \mathrm{Luk}, \tau}$ be the set of all recursively extended bivalent truth-valuations over formulas of $\mathscr{L}_{2 . \mathrm{Luk}, \tau}$ that satisfy the equivalence axioms of $\mathrm{Ax}_{\mathrm{Luk}}$. Then we can prove:

(4) Theorem $\left(\mathrm{L}_{3}\right.$ into $\left.\mathrm{L}_{2}\right)$ :

4.1 For every three-valued valuation function $\mathrm{val}_{3} \in \mathrm{Val}_{3}$ there exists exactly one two-valued valuation function $\mathrm{val}_{2}={ }_{\operatorname{def}} \mathrm{f}\left(\mathrm{val}_{3}\right) \in \mathrm{Val}_{2 . \mathrm{Luk}, \tau}$ (f an injective function) such that for every $\mathscr{L}_{3}$-formula A

$$
\operatorname{val}_{3}(\mathrm{~A})=\mathrm{o} \text { iff } \operatorname{val}_{2}(\mathrm{O}(\mathrm{A}))=\mathrm{t}, \text { where } \mathrm{O}=\mathrm{T} / \mathrm{U} / \mathrm{F} \text { iff } \mathrm{o}=\mathrm{t} / \mathrm{u} / \mathrm{f}
$$

4.2 An $\mathscr{D}_{3}$-statement $\mathrm{A}$ is logically true in $\mathrm{L}_{3}$ iff $\mathrm{T}(\mathrm{A})$ follows logically from $\mathrm{Ax}_{\mathrm{Luk}}$ in $\mathrm{L}_{2}$, and analogously for logical consequence. Thus

$$
\begin{gathered}
\mid=={ }_{\text {L3 }} \text { A iff } \operatorname{Ax}_{\mathrm{Luk}} \mid=={ }_{\mathrm{L} 2} \tau(\mathrm{A}) \text {, and } \\
\Gamma \mid=={ }_{\mathrm{L} 3} \mathrm{~A} \text { iff } \mathrm{Ax}_{\mathrm{Luk}} \cup \tau(\Gamma) \mid=={ }_{\mathrm{L} 2} \tau(\mathrm{A}) \text {, where } \tau(\Gamma)=_{\operatorname{def}}\{\tau(\mathrm{B}): \mathrm{B} \in \Gamma\} .
\end{gathered}
$$

According to theorem 4.2 the translation function is conservative in the sense of Carnielli et al. [12]. The proof of theorem (4) is based on two lemmata:

Lemma 1 There exists an injective function $\mathrm{f}: \mathrm{Val}_{3}(\mathrm{~L}) \rightarrow \mathrm{Val}_{2 . \mathrm{Luk}, \tau}$ whose restriction to propositional atoms satisfies

$(*)$ for all $\mathrm{p} \in \wp: \operatorname{val}_{3}(\mathrm{p})=\mathrm{o}$ iff $\operatorname{val}_{2}(\mathrm{Op})=\mathrm{t}$, where $\mathrm{O}=\mathrm{T} / \mathrm{U} / \mathrm{F}$ iff $\mathrm{o}=\mathrm{t} / \mathrm{u} / \mathrm{f}$.

Proof For every $\mathrm{val}_{3} \in \mathrm{Val}_{3}(\wp)$, we define $\mathrm{f}\left(\mathrm{val}_{3}\right)=\mathrm{val}_{2} \in \mathrm{Val}_{2 . \mathrm{Luk}}(\mathrm{O} \wp)$ by the condition (*). The definition satisfies the axiom $\mathrm{T}(\mathrm{A}) \dot{\mathrm{V}} \mathrm{U}(\mathrm{A}) \dot{\mathrm{V}} \mathrm{F}(\mathrm{A})$. The bijection $\mathrm{f}$ extends uniquely to all $\mathscr{B}_{3}$-formulas by the requirement that val ${ }_{2}$ satisfies the equivalence axioms in $\mathrm{Ax}_{\mathrm{Luk}}$; this requirement determines the truth values of the translations of all $\mathscr{D}_{3}$-formulas and their $\mathrm{Ax}_{\mathrm{Luk}}$-equivalents in $\mathscr{D}_{2 . \mathrm{Luk}, \tau}$. Q.E.D.

Lemma 2 For every $\mathrm{A} \in \mathrm{L}_{3}$ with $\wp(\mathrm{A})=\left\{\mathrm{p}_{1}, \ldots, \mathrm{p}_{\mathrm{n}}\right\}, \mathrm{Ax}_{\mathrm{Luk}} \mathrm{L}_{2}$-entails that $\mathrm{O}(\mathrm{A})$ is equivalent with a distinguished disjunctive and negationless normal form $\mathrm{DN}(\mathrm{OA})$, each elementary disjunct being a conjunction of modalized variables $\mathrm{O}_{1} \mathrm{p}_{1} \wedge \ldots \wedge \mathrm{O}_{n} \mathrm{p}_{\mathrm{n}}$ (the 'trivalent constituents'). 
Proof By successive application of the equivalence transformations corresponding to the axioms of $\mathrm{Ax}_{\mathrm{Luk}}$, one can drive the truth-value operators successively inside the formula until they stand immediately before the unmodalized variables; negations are thereby eliminated. ${ }^{9}$ By applying $\wedge-\vee$ distribution laws and expanding conjuncts in which certain modalized variables $\mathrm{Op}_{\mathrm{i}}$ in $\mathrm{O} \wp(\mathrm{A})$ are missing (by replacing such a conjunct $\mathrm{X}$ by $\left.\left(\mathrm{X} \wedge \mathrm{T} \mathrm{p}_{\mathrm{i}}\right) \vee\left(\mathrm{X} \wedge \mathrm{U} \mathrm{p}_{\mathrm{i}}\right) \vee\left(\mathrm{X} \wedge \mathrm{Fp} \mathrm{p}_{\mathrm{i}}\right)\right)$, one can produce the required disjunction of trivalent constituents, abbreviated as $\mathrm{DN}(\mathrm{OA})$. Q.E.D.

Proof of Theorem 4.1 Let $A \in \mathscr{D}_{3}$. The proof rests on the fact that every line ('val ${ }_{3}$ ') of A's trivalent truth table with $\operatorname{val}_{3}(A)=$ o corresponds exactly to one of $\mathrm{O}(\mathrm{A})$ 's trivalent constituents in $L_{2}$. Here is the formal proof: $\operatorname{val}_{3}(A)=0$ iff $v a_{3} \mid==O(A)$ iff $v a_{3} \mid==$ $\mathrm{DN}(\mathrm{OA})$ ( since $\mathrm{val}_{3} \mid==\mathrm{A} \leftrightarrow \mathrm{DN}(\mathrm{OA})$ ) iff $\mathrm{val}_{3} \mid==\mathrm{C}$ for some conjunct $\mathrm{C}$ of $\mathrm{DN}(\mathrm{OA})$ iff $\mathrm{val}_{2}=\mathrm{f}\left(\mathrm{val}_{3}\right)$ verifies $\mathrm{C}$ (by lemma 1 ) iff $\mathrm{val}_{2} \mid==\mathrm{DN}(\mathrm{OA})$ iff $\mathrm{val}_{2} \mid==\mathrm{O}(\mathrm{A})$ (by lemma 2). Q.E.D.

Proof of Theorem $4.2 \mid=={ }_{\mathrm{L} 3} \mathrm{~A}$ iff $\forall \mathrm{val}_{3} \in \mathrm{Val}_{3}$ : $\mathrm{val}_{3} \mid==\mathrm{A}$ iff $\forall \mathrm{val}_{2} \in \mathrm{Val}_{2 . \mathrm{Luk} . \tau}: \mathrm{val}_{2} \mid==$ TA (by theorem 4.1) iff $\mid==_{\mathrm{L} 2} \tau(\mathrm{A})$. - Analogously for inferences. Q.E.D.

\subsection{Discussion of the Proposed Translation Method}

In the next four subsections we discuss subtleties and achievements of the proposed translation method.

\subsubsection{Meaning Preservation}

Our translation preserves meaning as well as possible. It is not literally possible to translate a three-valued atomic proposition $p$ into a two-valued logic, because in $\mathrm{L}_{2}$ it has only two but in $\mathrm{L}_{3}$ it has three truth values. What can be literally translated, however, are the more fine-grained propositions Tp, Up and Fp, whose meaning is strictly the same in $\mathrm{L}_{3}$ and in $\mathrm{L}_{2}$. This makes it possible to translate all assertions expressible in $\mathrm{L}_{3}$, given the truth view of assertions. Moreover, by applying the $\mathrm{Ax}_{\mathrm{Luk}^{-}}$ equivalences (that are valid in $\mathrm{L}_{2}$.Luk as well as in $\mathrm{L}_{3}$ ), the semantic composition of $\mathrm{A}$ in $\mathrm{L}_{3}$ is fully reflected in $\mathrm{L}_{2}$. We conclude that every proposition that can be expressed in $L_{3}$ can be also expressed in $L_{2}$.

Kooi and Tamminga [37] also use a translation function for truth-value assertions in their translation of $\mathrm{L}_{3}$ into the modal logic $\mathrm{S} 4$. Their translation differs from ours in two respects: First, they translate the truth-value assertions Tp, Up and Fp into the modal

\footnotetext{
${ }^{9}$ Here is the formal inductive proof: We must show that $(*)$ for every $O_{i} \in\{T, U, F\}, A_{\text {Luk }} \mid==O_{i}(A) \leftrightarrow A^{\prime}$ holds, where $\mathrm{A}^{\prime}$ satisfies the condition $(* *)$ that all $\mathrm{O}_{\mathrm{i}}$ stand in front of propositional atoms. Induction hypothesis: Assume $(*)$ is proved for all $\mathrm{O}_{\mathrm{i}}(\mathrm{A})$ formulas of degree $\mathrm{n}$, where "degree(A)" is the maximal number of propositional operators in the scope of a truth operator in A. Induction step: Assume $\mathrm{O}_{\mathrm{i}}(\mathrm{A})$ has degree $\mathrm{n}+1$. Then $\mathrm{A}$ has one of the forms $\neg \mathrm{B}, \mathrm{B} \wedge \mathrm{C}, \mathrm{B} \vee \mathrm{C}$ or $\mathrm{B} \rightarrow \mathrm{D}$. By applying the respective $\mathrm{Ax}_{\mathrm{Luk}}$ equivalence axioms, $\mathrm{O}_{\mathrm{i}}(\mathrm{A})$ is $\mathrm{Ax}_{\mathrm{Luk}}$-equivalent with the corresponding formula schemata $\mathrm{A}^{\prime \prime}$ at the right side, whose degree is $n$. By induction hypothesis we can replace every subformula $E$ of $A^{\prime \prime}$ of degree $n$ by a subformula E' satisfying condition (**). This replacement leads to a formula $\mathrm{A}^{\prime}$ equivalent with $\mathrm{O}_{\mathrm{i}}(\mathrm{A})$ and satisfying $(* *)$. Q.E.D.
} 
S4-sentences $\square \mathrm{p}, \diamond \mathrm{p} \wedge \neg \square \mathrm{p}$ and $\neg \square \mathrm{p}$, respectively (ibid., 1064), while we use the intensional operators T, U and F. Second, they build the equivalences that we expressed by means of the axioms $\mathrm{Ax}_{\mathrm{Luk}}$ directly into their translation function for complex $\mathrm{L}_{3}$ sentences, by translating a complex $\mathrm{L}_{3}$-sentence directly into the disjunction of its modal constituents, while we proved in lemma 2 that a sentence is $A_{x_{L u k}}$-equivalent with this disjunction. We prefer our translation method for the epistemological reason that it makes the embedding of $\mathrm{L}_{3}$ into an axiom set in $\mathrm{L}_{2 \text {.Luk }}$ explicit.

\subsubsection{Holistic Nature of the Translation}

The deeper reason behind the 'holistic' nature of our translation function is the fact that in $\mathrm{L}_{3}$ the correspondence schema of truth is no longer valid: TA $\leftrightarrow A$ has the value $f$ if $A$ has the value $\mathrm{u}$, since $\mathrm{f} \leftrightarrow \mathrm{u}=\mathrm{f}$. In combination with the truth view of assertion this implies that a three-valued proposition and the assertion of this proposition are not logically equivalent. Therefore the translation of A by T(A) cannot be applied in a recursive fashion. For example, the assertion " $p$ " is translated as "Tp" (because this is what "p" asserts), but the assertion " $\neg \mathrm{p}$ " cannot be recursively translated as " $\neg \mathrm{Tp}$ ", because what it asserts is "T $(\neg p)$ " ( $\operatorname{val}(p)=f)$ and this is stronger than $\neg T p(v a l(p) \in\{u, f\})$. This epistemological subtlety has been reflected in early writings about three-valued logic, e.g. in Woodruff's distinction between a strong and a weak mode of assertion ([72], 122).

\subsubsection{Comparison with the Literature}

The expansion of classical truth-functional logic by the intensional operators $\mathrm{T}, \mathrm{U}, \mathrm{F}$ makes it possible to preserve the meaning of $\mathrm{L}_{3}$-assertions. This meaning-preservation feature distinguishes my account from most translation functions between logics studied in the literature (for an overview cf. [12]). In these studies, translations are usually not accompanied by expansions of the (classical) language, at the cost that the translation functions do not preserve the meaning and semantic composition of the translated statements; they only preserve the consequence operation. One example is the abstract translation functions studied by Jerábek [35]. These translation functions map the formulas of the language $\mathscr{B}$ of a propositional logic $\mathrm{L}$ into formulas of a language $\mathscr{D}$ ' of a logic $\mathrm{L}$ ', such that if $A \models_{L} B$, then $\left.f(A)\right|_{L}, f(B)$, roughly speaking as follows: given an enumeration of all $\mathscr{D}$-formulas and the nth formula $\mathrm{A}_{\mathrm{n}}$ of $\mathscr{B}, \mathrm{f}\left(\mathrm{A}_{\mathrm{n}}\right)$ is defined as $\mathrm{X} \vee\left(\mathrm{q}_{\mathrm{n}} \wedge \mathrm{Y}\right)$, where $\mathrm{X}$ is the disjunction of the translations of all premises with indices smaller than $n$ that entail $A_{n}, q_{n}$ is a new variable and $Y$ is the conjunction of all translations of implications $\mathrm{C} \rightarrow \mathrm{D}$ with indices smaller than $\mathrm{n}$ such that $\left\{\mathrm{C}, \mathrm{A}_{\mathrm{n}}\right\}$ entails $\mathrm{D}$ (ibid., 669). Jerábek [35] proves that $\mathrm{L}_{2}$ is translation-universal in the sense that every finitary deductive system in countably many formulas can be conservatively translated into $\mathrm{L}_{2}$. Many other but not all non-classical propositional logics are translation-universal in this sense. These results are technically impressive. However, the defender of a non-classical logic can object that the translation is not meaning-preserving; it does not reflect what the non-classical assertions express and thus is not suitable for the epistemic purpose of an optimality justification in regard to representation power.

An example of a non-meaning-preserving translation at the semantic level is the reduction of many-valued logics to bivalent logics proposed by Suszko [67]. Given a many-valued logic with a subset Des $\subset$ Val of designated truth values, Suszko proposed 
to translate the disjunction (or set) of the designated truth-values into the bivalent value "true" and the disjunction (or set) of the non-designated truth-values into "false". Suszko's translation is useful for many purposes (cf. [5]). However, Suszko's translation does not preserve the meaning of the propositional connectives; they become intensional under Suszko's bivalent semantics ([45], 79; [70]). For example, both p and $\neg \mathrm{p}$ may have the truth-value false; thus the law of excluded middle, $\mathrm{p} \vee \neg \mathrm{p}$, is no longer valid in Suszko's bivalent semantics. Therefore Suszko's bivalent semantics is not classical and does not yield a translation of $\mathrm{L}_{3}$ into a classical logic.

\subsubsection{Bridge Axioms between $L_{3}$ and $L_{2}$}

For every $\mathrm{S} \in \mathrm{L}_{3}$, the truth value of $\mathrm{T}(\mathrm{S})$ depends only on the truth values of its modalized but not of its unmodalized variables. So far, the bivalent truth-values of the modalized variables $\left(\mathrm{O}_{\mathrm{i}} \mathrm{p}\right)$ have not been related to the bivalent truth-values of the unmodalized variables. For the semantic coherence between $\mathrm{L}_{3}$ and $\mathrm{L}_{2}$ we require the following

(5) Bridge axioms (from $\tau\left(\mathrm{L}_{3}\right)$ to $\mathrm{L}_{2}$ ): Tp $\rightarrow \mathrm{p}$ and $\mathrm{Fp} \rightarrow \neg \mathrm{p}$.

In words, a trivalently true (or false) atomic sentence is also bivalently true (or false, respectively), while for undetermined sentences their bivalent truth value is left open. One can prove that (5) entails the validity of the bridge axioms TA $\rightarrow$ A and FA $\rightarrow \neg \mathrm{A}$ for all $\mathscr{L}_{3}$-formulas built up from $\neg, \wedge$ and $\vee$. Interestingly, the unrestricted bridge axioms may be violated for Lukasiewicz' implicational formulas ${ }^{10}$; but they are valid for Kleene's three-valued implications, which differ from Lukasiewicz' implications in having $\mathrm{u} \rightarrow \mathrm{u}=\mathrm{u}$ instead of $\mathrm{u} \rightarrow \mathrm{u}=\mathrm{t}$.

The converse implications $(\mathrm{p} \rightarrow \mathrm{Tp}$ and $\neg \mathrm{p} \rightarrow \mathrm{Fp}$ ) must not hold, since otherwise the translation would not be conservative and the translated three-valued logic would collapse into two valued logic: If we would accept the inverse bridge axioms, then $\mid==_{\mathrm{L} 2} \mathrm{p} \vee \neg \mathrm{p}$ would imply $\mid==_{\mathrm{L} 3} \mathrm{~T}(\mathrm{p} \vee \neg \mathrm{p})$ and thus $\mid==_{\mathrm{L} 3} \mathrm{p} \vee \neg \mathrm{p}$.

\subsection{Generalization to Many-Valued Logics}

Lukasiewicz' $\mathrm{L}_{3}$ was later mathematically generalized to many-valued logics with arbitrarily many 'truth-values', abstracting from a particular philosophical interpretation of these truth-values $[26,45]$. A multi-valued logic L in the generalized sense is semantically characterized by A set of truth-vales Val and a subset Des $\subset$ Val of designated truth-values; a formula $\mathrm{A}$ is defined as logically true if all possible valuations of the propositional variables assign to A a designated value. The triple $<$ Val, Des, $\left\{\mathrm{t}_{\mathrm{c}}: \mathrm{c} \in \mathrm{C}\right\}>$ is called a Val-valued logical matrix, with $\left\{\mathrm{t}_{\mathrm{c}}: \mathrm{c} \in \mathrm{C}\right\}$ being the set of truthtables for a set of connectives $\mathrm{C}$.

The translation strategy of sec. 3.1 applies to all many-valued logics that are representable by means of finitely many truth values. Thus, if an $n$-valued logic $L_{n}$ is based on a matrix $<\mathrm{Val}_{\mathrm{n}}, \operatorname{Des}_{\mathrm{k}},\left\{\mathrm{t}_{\mathrm{c}}: \mathrm{c} \in \mathrm{C}\right\}>$ with $\left|\mathrm{Val}_{\mathrm{n}}\right|=\mathrm{n},\left|\mathrm{Des}_{\mathrm{k}}\right|=\mathrm{k}<\mathrm{n}$ and $\mathrm{C}=\{\neg, \wedge, \vee, \rightarrow\}$, then we extend $\mathrm{L}_{2}$ by $\mathrm{n}$ intensional truth value operators $\mathrm{O}_{1}, \ldots, \mathrm{O}_{\mathrm{n}}$

\footnotetext{
$\overline{{ }^{10}}$ A counterexample: if $\operatorname{val}_{3}\left(\mathrm{p}_{1}\right)=\operatorname{val}_{3}\left(\mathrm{p}_{2}\right)=\mathrm{u}$, then $\operatorname{val}_{3}\left( \pm \mathrm{p}_{1} \rightarrow \pm \mathrm{p}_{2}\right)=\mathrm{t}$ and thus $\operatorname{val}_{2}\left(\mathrm{~T}\left( \pm \mathrm{p}_{1} \rightarrow \pm \mathrm{p}_{2}\right)\right)=\mathrm{t}$ for all $\pm \mathrm{p}_{\mathrm{i}} \in\left\{\mathrm{p}_{\mathrm{i}}, \neg \mathrm{p}_{\mathrm{i}}\right\}$; but $\operatorname{val}_{2}\left( \pm \mathrm{p}_{1} \rightarrow \pm \mathrm{p}_{2}\right)=\mathrm{t}$ can impossibly hold for all $\pm \mathrm{p}_{\mathrm{i}} \in\left\{\mathrm{p}_{\mathrm{i}}, \neg \mathrm{p}_{\mathrm{i}}\right\}$.
} 
together with the equivalence axioms describing $L_{n}$ 's truth tables for $\neg, \wedge, \vee$ and $\rightarrow$, and add the n-valent truth-value axiom $\mathrm{O}_{1}(\mathrm{~A}) \dot{\mathrm{v}} \ldots \dot{\mathrm{v}} \mathrm{O}_{\mathrm{n}}(\mathrm{A})$. For all many-valued logics it is natural to assume the designated-value view of assertions: asserting $\mathrm{p}$ in a many-valued logic means asserting that $\mathrm{p}$ has a designated value. Based on this view, we can then prove the translation theorem for the assertions of the many-valued logic $L_{n}$ in the same way as above, by demonstrating that $\mid==_{\mathrm{Ln}} \mathrm{A}$ iff $\mid==_{\mathrm{L} 2} \operatorname{Des}(\mathrm{A})$, with $\operatorname{Des}(\mathrm{A})$ abbreviating $\vee\left\{\mathrm{O}_{\mathrm{i}}(\mathrm{A}): \mathrm{v}_{\mathrm{i}} \in \mathrm{Des}_{\mathrm{k}}\right\}$ (and likewise for inferences). Of course, if the number of truth values is high, the disjunctive normal forms of the $\mathrm{L}_{2}$-translations of $\mathrm{L}_{\mathrm{n}}$-formulas become rather complex (for $\mathrm{m}$ propositional variables there are $\mathrm{n}^{\mathrm{m}}$ possible constituents). However, we conjecture that in many cases fewer intensional operators than truth values are needed to express the translation function; an investigation of this question is work for the future.

\section{Translating Paraconsistent and Intuitionistic Logics}

\subsection{Translating the Paraconsistent Logic LP}

As explained in sec. 1, the major motivation of paraconsistent logics is to admit the possibility of statements that are both true and false, but to prohibit the classically valid inference of 'explosion' or 'ex falso quod libet' (EFQ): $p \wedge \neg p$ / q. Not all but many paraconsistent logics can be characterized by means of finite truth value matrices ([52], sec. 3.6). The simplest paraconsistent logic is the logic of paradox, LP, developed by Priest [50]. It is a species of a three-valued logic, having instead of the third value "undetermined" the value "both true and false", abbreviated as b (or "p" for "paradoxical", as in [50]). The values " $\mathrm{t}$ " and "f" now mean "true only" and "false only", respectively. If " $u$ " is replaced by "b", then the three-valued matrices for the propositional connectives of LP are those of Kleene's [36] three-valued logic, which are 'almost' identical with Lukasiewicz' three-valued logic $\mathrm{L}_{3}$, with the exception of one line in the truth table for the implication, namely $b \rightarrow b=b$ (instead of $u \rightarrow u=t$, as in [44]). The important difference of LP compared to $\mathrm{L}_{3}$ is that LP considers both values $t$ and $\mathrm{b}$ as designated, which changes the resulting LP-valid theorems and inferences radically. One the one hand, LP's logical theorems are now identical with the theorems of classical logic, i.e., $\mathrm{LP}=\mathrm{L}_{2}$. For example, $\mathrm{p} \vee \neg \mathrm{p}$ is LP-true, since under all valuations $\mathrm{val}: \mathrm{P} \rightarrow \mathrm{Val}$, val $(\mathrm{p} \vee \neg \mathrm{p})$ comes out either as $\mathrm{t}$ or as $\mathrm{b}$. On the other hand, many classically valid inferences become invalid. For example, (EFQ) $\mathrm{p} \wedge \neg \mathrm{p} \mid==\mathrm{q}$ is invalid, since there are valuations assigning $\mathrm{b}$ to $\mathrm{p}$ and thus to $\mathrm{p} \wedge \neg \mathrm{p}$, but $\mathrm{f}$ to $\mathrm{q}$. While the elimination of (EFQ) is the central intended feature of LP, four further highly plausible

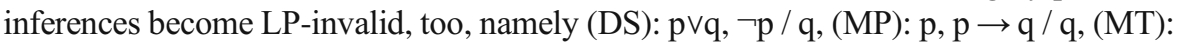
$\mathrm{p} \rightarrow \mathrm{q}, \neg \mathrm{q} / \neg \mathrm{p}$ and $($ Trans $\rightarrow): \mathrm{p} \rightarrow \mathrm{q}, \mathrm{q} \rightarrow \mathrm{r} / \mathrm{p} \rightarrow \mathrm{r}([50], 228)$.

In spite of these differences, the strategy of translating the logic LP into classical logic $L_{2}$ is the same as for $L_{3}$ as outlined in section 3.1: we extend $\mathscr{D}_{2}$ by the three intensional operators $\mathrm{T}$ (true only), $\mathrm{B}$ (both true and false) and $\mathrm{F}$ (false only) and represent their truth-tables as axioms of the modal theory $\mathrm{Ax}_{\mathrm{LP}}$ in the extended

language $\mathscr{b}_{2 \text {.para. }}$. As in all other many-valued logics, we translate LP's assertions into $\mathrm{L}_{2}$ based on the designated-value view of assertions. Let " $\mathrm{D}(\mathrm{A})$ " stand for "A has a designated truth value", being an abbreviation for "T(A) $\vee \mathrm{B}(\mathrm{A})$ ". Then we can prove a 
translation theorem analogously to theorem (4), but with $\mathrm{T}(\mathrm{A})$ and $\mathrm{T}(\Gamma)$ replaced by $\mathrm{D}(\mathrm{A})$ and $\mathrm{D}(\Gamma)$, respectively (where $\mathrm{D}(\Gamma):=\{\mathrm{D}(\mathrm{B}): \mathrm{B} \in \Gamma\})$ :

(6) Theorem (LP into $\left.\mathrm{L}_{2}\right): \Gamma \mid==_{\mathrm{LP}} \mathrm{A}$ iff $\operatorname{Ax}_{\mathrm{LP}} \cup \mathrm{D}(\Gamma) \mid==_{\mathrm{LP}} \mathrm{D}(\mathrm{A})$.

Based on this translation we can show, for example, that $D(p \wedge \neg p) \mid=/=D(q)$, and likewise that $\mathrm{D}(\mathrm{p} \vee \mathrm{q}), \mathrm{D}(\neg \mathrm{p}) \mid=/=\mathrm{D}(\mathrm{q})$ and $\mathrm{D}(\mathrm{p} \rightarrow \mathrm{q}), \mathrm{D}(\mathrm{p}) \mid=/=\mathrm{D}(\mathrm{q})$ (etc.), i.e., the translations of LP-invalid inferences come out as invalid, too.

So far the situation seems to be similar as that for Lukasiewicz' $\mathrm{L}_{3}$, but there is a deep hidden difference: While the trivalent truth operators $T, U$ and F, whose values are always bivalent, are explicitly definable in $\mathrm{L}_{3}$, the corresponding truth operators $\mathrm{T}, \mathrm{B}$ and $\mathrm{F}$ are undefinable in LP - ultimately because of the tiny difference that $b \rightarrow b=b$ (instead of $t)$. This makes it impossible to define " $B p$ " via “ $(p \vee \neg p) \rightarrow(p \wedge \neg p)$ " and implies that "Tp" and "Fp" are also undefinable in LP. Therefore, the translation of LP into $L_{2}$ yields a proper expressive extension of LP: in $L_{2} \cup A x_{L P}$ we can express and prove inferences that are inexpressible in LP. For example, we can prove

$$
\text { (7) } \mathrm{T}(\mathrm{p} \wedge \neg \mathrm{p})\left|=={ }_{2} \mathrm{Tq}, \quad \mathrm{T}(\mathrm{p} \vee \mathrm{q}), \mathrm{T}(\neg \mathrm{p})\right|=={ }_{2} \mathrm{Tq}, \quad \mathrm{T}(\mathrm{p} \rightarrow \mathrm{q}), \mathrm{Tp} \mid=={ }_{2} \mathrm{Tq}
$$

which are the T-modalized versions of EFQ, DS and MP, that are valid in LP, but inexpressible in LP. Proponents of LP may see this as a disadvantage, but we see it as an advantage, because 'true-only'-assertions are part of LP's semantics, so why should these assertions not also be expressible in the object language? But within LP it is impossible to find formulas that are necessarily bivalent, i.e. either true or false but not both. A consequence of this expressive weakness of LP explained in section 6 is that it makes an inverse translation of $\mathrm{L}_{2}$ into LP impossible.

\subsection{Translating Intuitionistic Logic into S4}

As explained in sec. 1, in intuitionistic logic $\mathrm{L}_{\mathrm{i}}$ the classical notions of truth and falsity are replaced by the concepts of mathematical verification and falsification, where a verification of $p$ consists in a constructive proof with conclusion $p$, and a falsification in a constructive proof from the assumption $\mathrm{p}$ to a contradiction $\mathrm{q} \wedge \neg \mathrm{q}$. Since by the results of Gödel and Church there exist mathematical propositions whose truth value is undecidable, this has the consequence that certain laws of classical logic are no longer valid, foremost the laws of double negation $(\neg p \rightarrow p)$ and of excluded middle $(p \vee \neg p)$. Intuitionistic logic cannot be algebraically represented by finite matrices [23]; thus the translation strategy of sec. 3 does not apply. A well-known 'translation' of $\mathrm{L}_{\mathrm{i}}$ into $\mathrm{L}_{2}$ is based on Glivenko's double-negation theorem: $\Gamma \mid===_{2}$ A iff $\neg \neg(\Gamma) \mid===_{i} \neg \neg$ A (with $\neg \neg(\Gamma)=\{\neg \neg \mathrm{B}: \mathrm{B} \in \Gamma\}$ ). Since this translation does not preserve meaning (as $\mathrm{p}$ and $\neg \neg \mathrm{p}$ mean different propositions in $\mathrm{L}_{\mathrm{i}}$ ), it is not suitable for our purpose. There is, however, a well-known translation of $\mathrm{L}_{\mathrm{i}}$ into a modal extension of $\mathrm{L}_{2}$, namely into the modal logic S4, that fits perfectly into our account of meaning-preserving translations of the non-classical assertions. The philosophical characteristics of intuitionistic logic, as opposed to classical or many-valued logics, is that it replaces the truth view of assertion by the provability view of assertion: asserting that $\mathrm{p}$ in $\mathrm{L}_{\mathrm{i}}$ means to assert that 
$\mathrm{p}$ has a constructive proof. Thus it is natural to translate the assertion that $\mathrm{p}$ in intuitionistic logic by $\square$, where the modal operator " $\square$ " is understood (not as metaphysical necessity, but) as constructive provability. As in the translation of manyvalued logics, this translation gives us bivalence outside the provability operator: although $\square \mathrm{p} \vee \square \neg \mathrm{p}$ is not L-true, $\square \mathrm{p} \vee \neg \square \mathrm{p}$ is again L-true.

Constructive provability satisfies the laws of the modal logic S4, semantically characterized by the class of reflexive and transitive Kripke frames (W,R) (i.e., the accessibility relation $\mathrm{R} \subseteq \mathrm{W}^{2}$ between worlds is reflexive and transitive). The $\mathrm{S} 4$-axioms are (T): $\square \mathrm{A} \rightarrow \mathrm{A}$ (what is provable is true, corresponding to reflexivity), (4): $\square \mathrm{A} \rightarrow \square \square \mathrm{A}$ (provability of propositions is itself provable, corresponding to transitivity), and the axioms and rules satisfied by all Kripke frame logics, namely $(\mathrm{K}): \square(\mathrm{p} \rightarrow \mathrm{q}) \rightarrow(\square \mathrm{p} \rightarrow$ $\square$ q) and $(\mathrm{N})|==\mathrm{A} /|==\square \mathrm{A}$.

Before we turn to the syntactic translation of $\mathrm{L}_{\mathrm{i}}$ into $\mathrm{S} 4$ we briefly recapitulate how the Kripke semantics for $\mathrm{L}_{\mathrm{i}}$ implements the translation idea in a semantic fashion ([47], sec. 5.1). The worlds of these frames are interpreted as epistemic states and the accessibility relation $\mathrm{R}$ expresses a natural (e.g. temporal) successor relation between these states. The valuation function over these frames is merely partial: a propositional atom may either be intuitionistically true or false or undefined at a world $\alpha$. This makes sense, since intuitionistic truth means provable truth, but not every $\mathrm{p}$ is either provable or disprovable, i.e., $\mathrm{p} \vee \neg \mathrm{p}$ is not $\mathrm{L}_{\mathrm{i}^{-}}$ true. Since intuitionistic truth is provable truth, the valuation function val has to satisfy the following constraint: if $p$ is intuitionistically true at a state $\alpha(\alpha \mid==p)$, then $\mathrm{p}$ is true at all states $\beta$ accessible from $\alpha(\mathrm{R} \alpha \beta$ implies $\beta \mid==\mathrm{p})$. Intuitionistic truth of conjunction and disjunction is recursively defined as classical truth, i.e. $\alpha \mid==\mathrm{A} \wedge \mathrm{B} / \mathrm{A} \vee \mathrm{B}$ iff $\alpha \mid==\mathrm{A}$ and/or $\alpha \mid==\mathrm{B}$. Intuitionistic truth of negation and implication, however, is more subtle: $\alpha \mid==\neg \mathrm{A}$ iff for no $\beta$ accessible from $\alpha, \beta \mid==$ A holds (i.e., every $\beta$ accessible from $\alpha$ can access a world in which $\mathrm{A}$ is not intuitionistically true), and $\alpha \mid==\mathrm{A} \rightarrow \mathrm{B}$ iff for every world $\beta$ accessible from $\alpha, \beta \mid==A$ implies $\beta \mid==B$. Kripke [39] proved that $L_{i}$ is complete for this semantics, using a classical metalogic. ${ }^{11}$

By transforming the Kripke semantics for $\mathrm{L}_{\mathrm{i}}$ into corresponding syntactical formulas, one arrives at the famous translation function from $\mathrm{L}_{\mathrm{i}}$-assertions into $\mathrm{S} 4$-assertions ([55], 265):

(8) Translation $(\tau)$ from $\mathrm{L}_{\mathrm{i}}$ to $\mathrm{S} 4$ :

$\tau(\mathrm{p})=\square \mathrm{p}($ for all propositional atoms $\mathrm{p} \in \wp)$

$\tau(\neg \mathrm{A})=\square \neg \tau(\mathrm{A})$

$\tau(\mathrm{A} \wedge \mathrm{B})=\tau(\mathrm{A}) \wedge \tau(\mathrm{B})$

$\tau(\mathrm{A} \vee \mathrm{B})=\tau(\mathrm{A}) \vee \tau(\mathrm{B})$

$\tau(\mathrm{A} \rightarrow \mathrm{B})=\square(\tau(\mathrm{A}) \rightarrow \tau(\mathrm{B}))$

The translation function (8) can be compactified as follows: $\tau(\mathrm{A})$ results from boxing all subformulas of $\mathrm{A}$ that are either atoms, negations or implications. For example, $\tau(\neg \mathrm{p})=\square \neg \square \mathrm{p}=\square \vee \neg \mathrm{p}, \tau(\mathrm{p} \vee \mathrm{q})=\square \mathrm{p} \vee \square \mathrm{q}, \tau(\mathrm{p} \rightarrow \mathrm{q})=\square(\square \mathrm{p} \rightarrow \square \mathrm{q})$, and $\tau((\mathrm{p} \rightarrow \neg \mathrm{q}) \wedge \mathrm{r})=$

${ }^{11}$ Kreisel [38] showed that there is no purely intuitionistic completeness proof for intuitionistic predicate logic (cf. [47] s. 5.1). 
$\square(\square \mathrm{p} \rightarrow \square \neg \square \mathrm{q}) \wedge \square \mathrm{r})$. With this translation function the following translation theorem has been proved [46]:

(9) Theorem( $\mathrm{L}_{\mathrm{i}}$ into $\left.\mathrm{S} 4\right): \Gamma \mid==_{\mathrm{i}} \mathrm{A}$ iff $\tau(\Gamma) \mid==_{\mathrm{S} 4} \tau(\mathrm{A})$.

For example, $\mid=/=_{S 4} \tau(p \vee \neg p)$ holds, since $\tau(p \vee \neg p)=p \vee \neg p$ and $\mid=/=_{S 4} p \vee \neg p$.

The major philosophical conclusion of this translation of $\mathrm{L}_{\mathrm{i}}$ into $\mathrm{S} 4$ is that the logic of mathematical verification may also be represented within an extended classical logic. This seems to refute Bueno's thesis that "if we want to accommodate the constructive features of mathematical reasoning, classical logic will be clearly inadequate" ([10], 108).

\section{Translating Quantum Logics}

\subsection{Quantum-Logical Disjunction and Negation}

Quantum logic intends to explicate the structure of 'experimental' propositions about quantum-physical systems, having the form "the magnitude $\mathrm{m}$ of system $\mathrm{x}$ has value $\mathrm{v}$ ", in short "m(x) = v" (cf. [69]). For example, m(x) can be the (real-valued) position or the (discrete-valued) spin of an electron $\mathrm{x}$. The system $\mathrm{x}$ is described by its physical state or wave-function $\psi(\mathrm{x})$ (the set of all possible states is called 'Hilbert space'). Each magnitude $\mathrm{m}$ corresponds to an operator $\mathrm{M}$ describing $\mathrm{M}$ 's measurement whose application to $\psi(\mathrm{x})$ determines the value of $\mathrm{m}(\mathrm{x})$ either (i) sharply, in which case $\psi(\mathrm{x})$ is a pure state w.r.t. the magnitude $\mathrm{m}$ and $\mathrm{m}$ is an 'eigenvalue' of $\mathrm{M}$ (i.e., $\mathrm{M} \psi(\mathrm{x})=\mathrm{m} \cdot \psi(\mathrm{x})$ holds), or (ii) merely probabilistically, in which case $\psi(\mathrm{x})$ is in a so-called superposition (or 'entangled') state w.r.t. $\mathrm{m}$, meaning that $\psi$ is a linear combination of two or more pure states w.r.t. $\mathrm{m}$. In this case a measurement of $\mathrm{m}$ changes the systems's state from a superposition state to a pure state for one of the possible values of $\mathrm{m}$ according to a probability distribution derivable from computing $\mathrm{M} \psi$; this measurement-induced change is also called the 'collapse' of the wave function.

Importantly, certain pairs of quantum-physical magnitudes cannot simultaneously have a sharp value. For example, according to Heisenberg's uncertainty relation it is impossible that both the position s and the momentum $\mathrm{p}$ can both be sharply realized: thus if $\psi(x)$ is a pure state w.r.t. p, it is a superposition state w.r.t. s. It is the crucial feature of the standard version of quantum logic (QL) going back to Birkhoff and von Neumann [6] that the superposition state of a system is expressed as a non-classical disjunction $\left(\mathrm{V}_{\mathrm{q}}\right)$ of pure states. Thus, if the electron in a two-slit experiment is in a superposition of the two possible positions states $\mathrm{s}_{\mathrm{r}}$ (going though the right slit) and $\mathrm{s}_{1}$ (going to the left slit), then QL describes this state as $s_{r} v_{q} s_{1}$. Note that this view of the matter is by no means mandatory: already early critics of QL objected that a superposition state is genuinely different from a (classical) disjunction of pure states ([49], 685; [22], 523). The defenders of QL replied that quantum disjunction is different from classical disjunction $(\mathrm{V})$ and that the description of superposition states by non-classical disjunctions has advantages for realism [54] as well as for empiricism [69]. 
Instead of entering this controversy we simply observe that the resulting quantumlogical disjunction is radically different from classical disjunction. Assume that the electron in the two-slit experiment is in the superposition state $\mathrm{s}_{\mathrm{r}} \mathrm{v}_{\mathrm{q}} \mathrm{s}_{1}$ and in the pure state p w.r.t. momentum, then QL describes this situation as $\mathrm{p} \wedge\left(\mathrm{s}_{\mathrm{r}} \mathrm{V}_{\mathrm{q}} \mathrm{s}_{\mathrm{l}}\right)$, but by the incommensurability of momentum and position, both conjunctions $\mathrm{p} \wedge \mathrm{s}_{\mathrm{r}}$ and $\mathrm{p} \wedge \mathrm{s}_{1}$ are false. Thus the expansion direction of the classical law of distribution, $\left(\mathrm{D}_{\mathrm{e}}\right): \mathrm{p} \wedge(\mathrm{q} \vee \mathrm{r}) \rightarrow$ $(\mathrm{p} \wedge \mathrm{q}) \vee(\mathrm{p} \wedge \mathrm{r})$, is invalid according to $\mathrm{QL}$.

Putnam [54] argued that the failure of $\left(\mathrm{D}_{\mathrm{e}}\right)$ would allow for a fully realistic interpretation of quantum physics, because we could now say that the electron is always in a definite position and momentum state; so the only mistake is accepting the logical law of distribution $\left(\mathrm{D}_{\mathrm{e}}\right)$. But as several authors (e.g., [16]) pointed out, this argument is flawed, because although the quantum-logical disjunction $\mathrm{s}_{\mathrm{r}} \mathrm{v}_{\mathrm{q}} \mathrm{s}_{\mathrm{l}}$ is true in the superposed state, both disjuncts of the disjunction are false ([69], 584; [13], 133). Thus quantum-logical disjunction $\mathrm{v}_{\mathrm{q}}$ is so radically different from classical disjunction that it may be better not to call it a disjunction at all [34]. The reason why many QL-laws - all except of ( $\left.D_{\text {exp }}\right)$ resemble the laws of $\mathrm{L}_{2}$ is that $\mathrm{QL}$ introduces a corresponding quantum-logic negation $\neg_{\mathrm{q}}$ that is likewise substantially different from classical negation $\neg$, but fits with $\vee_{\mathrm{q}}$ in similar ways as $\neg$ fits with $\vee$. Let $\Sigma$ be the Hilbert space (of a given quantum-physical system $\mathrm{x}$ ) and the semantical extension $\|\mathrm{A}\| \subseteq \Sigma$ of a quantum proposition $\mathrm{A}$ be defined as the set of states in $\Sigma$ verifying A. Then the extension of the quantum negation $\neg_{\mathrm{q}} \mathrm{A}$ is defined as the set of all states that are orthogonal to all states verifying A (where two state vectors $\alpha, \beta$ are orthogonal, in short: $\alpha \perp \beta$, if their scalar product is zero). Thus $\left\|\neg_{\mathrm{q}} \mathrm{A}\right\|$ is a proper subset of the extension $\Sigma-\|\mathrm{A}\|$ of classical negation, and $\left\|\left(\mathrm{A} \vee_{\mathrm{q}} \mathrm{B}\right)\right\|$ is a proper superset of the extension $\|\mathrm{A}\| \mathrm{U}\|\mathrm{B}\|$ of classical disjunction. Only the QL-extension of the conjunction $\wedge$ is the classical intersection, $\|\mathrm{A} \wedge \mathrm{B}\|=\|\mathrm{A}\| \cap\|\mathrm{B}\|$. As a consequence, the extensions of QLpropositions are always closed under linear combinations.

Because of these differences, it is broadly agreed that QL cannot replace classical logic: classical logic is needed to express the full structure and consequences of quantum physics $([65,29,3])$. On the other hand, quantum logic can express physical operations (e.g., linear combinations) that go beyond what classical logic can express. Moreover, there is no ordinary quantum implication ([13], 146-152). What is needed is a unified system containing the resources of both classical and quantum logic. Such a unification is possible by translating QL into an extension of classical logic, which is the topic of the next section.

\subsection{Two Possibilities of Translating Quantum Logics}

There are two well-established methods of translating QL into classical logic. The first method translates orthologic OL, which is a weakening of QL, into the modal logic B. This modal logic is semantically characterized by reflexive and symmetric Kripke frames and satisfies the axiom $(\mathrm{B}): \square \mathrm{A} \rightarrow \diamond \mathrm{A}$ (corresponding to the symmetry of $\mathrm{R}$ ) as well as $(\mathrm{T}),(\mathrm{K})$ and the rule $(\mathrm{N})$ (see sec. 4.2). OL results from classical logic by removing the expansion version of distribution $\left(\mathrm{D}_{\mathrm{e}}\right)$; algebraically $\mathrm{OL}$ is characterized by the class of ortholattices (Boolean lattices without distributivity, cf. [13], 137). QL strengthens OL by a weakened distribution law satisfied by the lattice of quantum propositions, namely 'orthomodularity' $(\mathrm{O}): \mathrm{p} \wedge\left(\neg \mathrm{q} \vee_{\mathrm{q}}(\mathrm{p} \wedge \mathrm{q})\right) \mid==_{\mathrm{QL}} \mathrm{q}$ (ibid., 142).

Dishkant [15] proved that OL is complete for the class of generalized KB-frames $<\mathrm{W}, \mathrm{R}, \Pi>$ whose worlds are physical states, whose accessibility relation is interpreted 
as the negation of orthogonality $(\operatorname{R} \alpha \beta$ iff not $\alpha \perp \beta)$, and whose algebra of admissible propositions $\Pi \subseteq \operatorname{Pow}(\mathrm{W})$ contains $\varnothing$ and $\mathrm{W}$, is closed under the operation of orthocomplement, $\mathrm{X}^{\mathrm{oc}}=_{\operatorname{def}}\{\alpha \in \mathrm{W}: \alpha \perp \mathrm{X}\}$ (the semantic counterpart of quantum negation), and satisfies the following condition:

(*) $\forall \beta \in \mathrm{R}_{\alpha} \exists \gamma \in \mathrm{R}_{\beta}(\gamma \in \mathrm{X}) \rightarrow \alpha \in \mathrm{X}$, for all $\mathrm{X} \in \Pi$

where $\mathrm{R}_{\delta}$ is the set of worlds R-accessible by world $\delta$ ([13], 139). Condition (*) guarantees closure of worlds under linear combinations and implies $\mathrm{X}=\left(\mathrm{X}^{\mathrm{oc}}\right)^{\mathrm{oc}}$. Generalized Kripke frames of this kind (with $\operatorname{val}\left(\neg_{\mathrm{q}} \mathrm{A}\right)=\|\mathrm{A}\|^{\text {oc }}$ and $\operatorname{val}(\mathrm{A} \wedge \mathrm{B})=$ $\operatorname{val}(\mathrm{A}) \cap \operatorname{val}(\mathrm{B}))$ are called orthoframes. Following from $(*)$ one can prove that a statement $A$ is true at a world $\alpha$ in an orthoframe $F$ if and only if $\square \vee A$ is true at $\alpha$ in F (ibid. 140, theorem 11), where the only-if direction is the non-trivial part (the ifdirection is an instance of axiom B). This fact leads directly to the method of translating OL-statements into the logic KB, characterized by reflexive-symmetric Kripke frames with the classical (i.e. unrestricted) algebra of propositions $(\Pi=\operatorname{Pow}(\mathrm{W}))$, namely by translating OL-statements into their 'necessarily-possibly'-variants as follows:

(10) Translation $(\tau)$ from OL into B:

$\tau(\mathrm{p})=\square \diamond \mathrm{p}($ for all propositional atoms $\mathrm{p} \in \wp)$

$\tau(\neg \mathrm{q} A)=\square \neg \tau(\mathrm{A})$

$\tau(\mathrm{A} \wedge \mathrm{B})=\tau(\mathrm{A}) \wedge \tau(\mathrm{B})$

$\tau\left(\mathrm{A} \vee_{\mathrm{q}} \mathrm{B}\right)==_{\text {def }} \tau\left(\neg_{\mathrm{q}}\left(\neg_{\mathrm{q}} \mathrm{A} \wedge \neg_{\mathrm{q}} \mathrm{B}\right)\right)=\square \neg(\square \neg \tau(\mathrm{A}) \wedge \square \neg \tau(\mathrm{B})) \leftrightarrow \square(\diamond \tau(\mathrm{A}) \vee \diamond \tau(\mathrm{B}))$.

Based on this translation one can prove $([24,13], 156$, theorem 53$)$ :

(11) Theorem (OL into B): $\Gamma \mid===_{O L} A$ iff $\tau(\Gamma) \mid=={ }_{B} \tau(A)$.

The second translation method does not only apply to OL but to full QL and is the most powerful one. It was developed by theoretical physicists [14, 18] and logicians $[2,3]$ and translates quantum logic into dynamic modal logic. This modal logic (abbreviated DML) extends the language of ordinary modal logic by a set of terms $a_{1}, a_{2}, \ldots$ denoting actions. Each action $a_{i}$ is semantically characterized by an accessibility relation $R_{a i}$ between worlds, expressing that performing action $\mathrm{a}_{\mathrm{i}}$ leads to a transition from the actual state $\alpha$ to an $R_{a i}$-accessible state $\beta$. For each action term a, [a] is the corresponding actionnecessity operator satisfying the standard axioms and rules $\mathrm{K}$ and $\mathrm{N}$ of Kripke modal logics; $\alpha \mid==[\mathrm{a}] \mathrm{A}$ expresses "A holds in all states produced by action a applied to state $\alpha$ " (and dually for $<\mathrm{a}>\mathrm{A}$ ). DML introduces three sorts of complex action terms: "a; b" for the sequential combination of a and $b$, definable as $[a ; b] A \leftrightarrow[a][b] A$, "a $a b$ " for indeterministic choice, definable as $[\mathrm{a} \cup \mathrm{b}] \mathrm{A} \leftrightarrow[\mathrm{a}] \mathrm{A} \wedge[\mathrm{b}] \mathrm{A}$, and the classical test operation? $\mathrm{A}$ ("is $\mathrm{A}$ true?"), characterized by reflexive or empty actions (depending on whether A is true or false) and definable as [?A]B $\leftrightarrow(\mathrm{A} \rightarrow \mathrm{B})$. Fine and Schurz [] proved that DML (without the loop-operator) is a definitional extension of a combined multimodal logic.

Dynamical logic is also suited to describe quantum measurements, which may change the underlying state if it is a superposed state. Dynamic quantum logic, in short DQL, arises 
from DML by leaving out the definition of the classical test operation and assuming instead two types of quantum actions: (i) quantum test operations $A_{1}$ ?, $A_{2}$ ?,.. for experimental propositions $A_{i}$ and (ii) unitary actions $a_{1}, a_{2}, \ldots$, describing undisturbed evolutions of nonstationary quantum systems (the latter actions are not needed for translating QL into $\mathrm{DQL}$ ). Experimental quantum propositions A are now translated as follows. "A holds in a state $\alpha$ " means that all A-tests applied to state $\alpha$ lead to a state in which A is true, which (as explained) can only hold if $\alpha$ is a pure A-state and A? applied to $\alpha$ leads back to $\alpha$ ([3], 297). “ $\neg \mathrm{q} A$ holds in a state $\alpha$ " means that no A-test applied to $\alpha$ leads to a positive result, i.e. every A-test fails. This is expressed in DQL as [A?] $\perp$, i.e., the test operation A? leads to nowhere (ibid. 298). Note that $[A$ ? $] \perp$ is stronger than the classical negation " $\neg A "$ expressing that not all tests of $A$ fail; moreover it satisfies the quantum law of double negation: $\alpha$ $\mid==\neg \mathrm{q} \neg \mathrm{q}$ iff all $([\mathrm{A}$ ?] $]$ )-tests applied to $\alpha$ fail iff $\alpha \mid==$ A. Conjunction is interpreted classically: " $\mathrm{A} \wedge \mathrm{B}$ " holds in $\alpha$ iff both $\mathrm{A}$ and $\mathrm{B}$ hold. With the mentioned definition of the indeterministic choice, the test condition for a conjunction, $(\mathrm{A} \wedge \mathrm{B})$ ?, can be expressed as

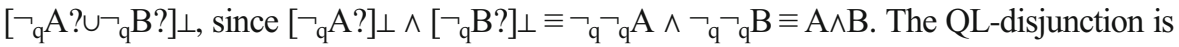
defined as $\mathrm{A} \vee_{\mathrm{q}} \mathrm{B}={ }_{\text {def }} \neg_{\mathrm{q}}\left(\neg_{\mathrm{q}} \mathrm{A} \wedge \neg_{\mathrm{q}} \mathrm{B}\right)$, being equivalent with $\left[\left(\left[\neg_{\mathrm{q}} \mathrm{A}\right.\right.\right.$ ? $] \perp \wedge\left[\neg_{\mathrm{q}} \mathrm{B}\right.$ ?] $\left.]\right)$ ? $] \perp$. The assertions of standard quantum logic can now be translated into DQL as follows:

(12) Translation $(\tau)$ from QL into DQL:

$$
\begin{aligned}
& \tau(\mathrm{p})=\mathrm{p} \\
& \tau\left(\neg_{\mathrm{q}} \mathrm{A}\right)=[\tau(\mathrm{A}) ?] \perp \\
& \tau(\mathrm{A} \wedge \mathrm{B})=\tau(\mathrm{A}) \wedge \tau(\mathrm{B}) \\
& \tau\left(\mathrm{A} \vee_{\mathrm{q}} \mathrm{B}\right)=\tau\left(\neg_{\mathrm{q}}\left(\neg_{\mathrm{q}} \mathrm{A} \wedge \neg_{\mathrm{q}} \mathrm{B}\right)\right), \mathrm{DQL}-\text { equivalent with }[([\tau(\mathrm{A}) ?] \perp \wedge[\tau(\mathrm{B}) ?] \perp) ?] \perp .
\end{aligned}
$$

With this translation one can show ([3], 301):

(13) Theorem (from QL into DQL): $\Gamma \mid==_{\mathrm{QL}} \mathrm{A}$ iff $\tau(\Gamma) \mid===_{\mathrm{QDL}} \tau(\mathrm{A})$.

Thus QL's non-classical operators $\neg_{\mathrm{q}}$ and $\vee_{\mathrm{q}}$ can be fully transformed into classical assertions about the results of dynamic quantum test operations. Since DQL contains the full resources of classical logic, it fits precisely our goal of offering a unified framework for representing the classical connectives as well as quantum operations. For example, in DQL one can express that a state $\alpha$ is superposed w.r.t. proposition $\mathrm{A}$ via $\alpha \mid==\neg[$ ?A $] \mathrm{A} \wedge \neg[$ ?A $] \perp$. Finally we mention that an equivalent translation of $\mathrm{QL}$ is also possible into predicate logic instead of DQL, since it is well known from modal correspondence theory that every modal formula can be equivalently translated into a formula of first or higher order predicate logic (cf. [57], sec. 2.3).

\section{Epistemological Conclusions and Discussion of Possible Objections}

We have shown that major kinds of non-classical logics are translatable into extended classical logic. We even conjecture that all non-classical logics can be translated into a suitably extended classical logic. Our reason for this conjecture is that all non-classical 
logics known to us can be semantically described in a classical ML. Further tests of this 'bold' conjecture are left to future work.

If our arguments are correct, they give us an optimality justification of classical logic: By using classical logic our conceptual representation system can only gain, but not lose, because if another logic has advantages for certain purposes, we can embed it into classical logic. What is primarily achieved by this result is the removal of the first threat mentioned in section 2: the threat of epistemic incommensurability. We rather have a situation of commensurability and 'pluralism in harmony'. In this harmonic logical pluralism, classical logic plays the role of a global unifying framework. One may counter that if classical logic were the only logic that could play this role, this would not speak for logical pluralism, but for logical monism. However, even if this were the case (see below), it would give us only a representational monism, but not a metaphysical monism, since it would still leave us the options of describing a particular domain by means of determinate or indeterminate, consistent or dialethic propositions (etc.), just that these options can now be realized within the classical framework. This result has significant consequences for the controversy on logical pluralism. For example, it makes it possible to overcome the restrictions of contextualism, insofar as non-classical and classical assertions, that according to contextualism can only be asserted in different contexts (cf. [11]), can now be simultaneously expressed in a unified 'context'. For example, in $\mathrm{L}_{2 . \mathrm{Luk}}$ we can express that a proposition $\mathrm{p}$ about the position-value of an electron in a superposition state is undetermined from a three-valued perspective but false from a two-valued perspective: $\mathrm{U}^{3} \mathrm{p} \wedge \mathrm{F}^{2} \mathrm{p}$. Assertions of this sort are of obvious importance for rational deliberations about which 'context' one should assume.

We now turn to consider possible limitations of our results. Let us first ask: Can the role of a unifying framework only be played by classical logic? This question leads us to the first of two possible objections considered in this final section.

\subsection{First Objection: The Possibility of Inverse Translation - Optimality without Dominance?}

The first objection points out that there may also be an inverse translation of classical logic into a non-classical logic. Before we investigate this question, let us clarify the possible reach of this objection: if it were true, it would not refute the optimality thesis, but merely the dominance thesis for classical logic.

The two notions come from game theory (cf. [60], sec. 5.7). A method (here a logic) is optimal in a given class of methods $\mathrm{M}$ iff it has maximal value in $\mathrm{M}$ in regard to the given goal, here linguistic representation power. Universal optimality coincides with optimality in the class of all methods. The optimality of a logic L does not exclude the possibility of other logics that have the same maximal value; thus there may be many logics which are equally optimal. This situation is only excluded if a logic L is dominant, which means that $\mathrm{L}$ has a higher value than all other logics.

Although optimality is not refuted by the intertranslatability objection, the objection is not fully defeated either. Our opponent may continue: if some non-classical logics are also optimal, what has been achieved by the optimality justification of classical logic? The answer was given above: the first threat, epistemic incommensurability, is defeated by optimality, but not the second threat, subjective relativism. If there are many equally representation-optimal logics $\mathrm{L}_{1}, \ldots, \mathrm{L}_{\mathrm{n}}$, and there are no further ceteris paribus 
preferences between them, then the rational choice among them is still undetermined and relative to subjective purpose or taste. As argued in section 2, given translatability, this sort of relativism would not be so disastrous, as we can always intertranslate - yet, given what we said in the preceding section, we would expect that some dominance arguments in favor of classical logic could also be given. Before we turn to this point (in section 6.3) we consider the possibilities of inverse translations in more detail.

Consider our paradigm example in section 3.1, the translation of Lukasiewicz $\mathrm{L}_{3}$ into classical $\mathrm{L}_{2}$. An inverse translation $\tau_{2 \rightarrow 3}$ is possible in complete analogy to $\tau_{3 \rightarrow 2}$ by extending $\mathscr{L}_{3}$ by two operators $\mathrm{T}^{2}$ and $\mathrm{F}^{2}$ of two-valued logics with the obvious truth tables in $\mathrm{L}_{2}$ (we write $\mathrm{t}^{2}, \mathrm{f}^{2}$ to distinguish two-valued from threevalued values):

\begin{tabular}{c|cc}
$\mathrm{p}$ & $\mathrm{T}^{2}(\mathrm{p})$ & $\mathrm{F}^{2}(\mathrm{p})$ \\
\hline $\mathrm{t}^{2}$ & $\mathrm{t}^{2}$ & $\mathrm{f}^{2}$ \\
$\mathrm{f}^{2}$ & $\mathrm{f}^{2}$ & $\mathrm{t}^{2}$
\end{tabular}

In $\mathrm{L}_{2}$ the two operators are explicitly definable as $\mathrm{T}_{2} \mathrm{~A} \leftrightarrow \mathrm{A}$ and $\mathrm{F}_{2} \mathrm{~A} \leftrightarrow \neg \mathrm{A}$. In $\mathrm{L}_{3}$, $\mathrm{T}^{2}$ and $\mathrm{F}^{2}$ figure as intensional operators axiomatized by the following set of axioms $\mathrm{Ax}_{\text {Class }}$ in the extended language $\mathscr{L}_{3 \text {.Class }}$ :

$$
\begin{array}{ll}
\mathrm{T}^{2}(\neg \mathrm{A}) \leftrightarrow \mathrm{F}^{2}(\mathrm{~A}) & \mathrm{F}^{2}(\neg \mathrm{A}) \leftrightarrow \mathrm{T}^{2}(\mathrm{~A}) \\
\mathrm{T}^{2}(\mathrm{~A} \wedge \mathrm{B}) \leftrightarrow \mathrm{T}^{2}(\mathrm{~A}) \wedge \mathrm{T}^{2}(\mathrm{~B}) & \mathrm{F}^{2}(\mathrm{~A} \wedge \mathrm{B}) \leftrightarrow \mathrm{F}^{2}(\mathrm{~A}) \vee \mathrm{F}^{2}(\mathrm{~B}) \\
\mathrm{T}^{2}(\mathrm{~A} \vee \mathrm{B}) \leftrightarrow \mathrm{T}^{2}(\mathrm{~A}) \vee \mathrm{T}^{2}(\mathrm{~B}) & \mathrm{F}^{2}(\mathrm{~A} \vee \mathrm{B}) \leftrightarrow \mathrm{F}^{2}(\mathrm{~A}) \wedge \mathrm{F}^{2}(\mathrm{~B}) \\
\mathrm{T}^{2}(\mathrm{~A} \rightarrow \mathrm{B}) \leftrightarrow \mathrm{F}^{2}(\mathrm{~A}) \vee \mathrm{T}^{2}(\mathrm{~B}) & \mathrm{F}^{2}(\mathrm{~A} \rightarrow \mathrm{B}) \leftrightarrow \mathrm{T}^{2}(\mathrm{~A}) \wedge \mathrm{F}^{2}(\mathrm{~B}) \\
\quad \mathrm{T}^{2}(\mathrm{~A}) \dot{\vee} \mathrm{F}^{2}(\mathrm{~A}) &
\end{array}
$$

Note that from $\mathrm{T}^{2}(\mathrm{~A}) \vee \mathrm{F}^{2}(\mathrm{~A})$ and $\mathrm{F}^{2}(\mathrm{~A}) \rightarrow \neg \mathrm{T}^{2}(\mathrm{~A})$ (following from $\mathrm{T}^{2}(\mathrm{~A}) \dot{\mathrm{V}} \mathrm{F}^{2}(\mathrm{~A})$ ) we can derive $T^{2}(A) \vee \neg T^{2}(A)$ within $L_{3} \cup A x_{\text {Class }}$; thus the $T^{2}$ - and $F^{2}$-modalized formulas of $\mathrm{L}_{3 . \text { Class }}$ are bivalent and satisfy the law of excluded middle.

The translation of $\mathscr{L}_{2}$ - into $\mathscr{D}_{3}$-formulas is again based on the truth view of assertion (which is adequate for all many-valued logics; recall sec. 3.3). Thus we translate:

$$
\text { (14) } \tau_{2 \rightarrow 3}(\mathrm{~A})=\mathrm{T}^{2}(\mathrm{~A}) \text {, for every } A \in \mathscr{B}_{2} \text {. }
$$

Some examples: $\tau(p)=T^{2} p, \tau(\neg p)=F^{2} p, \tau(p \vee \neg p)=T^{2}(p \vee \neg p) \leftrightarrow T^{2} p \vee F^{2} p, \tau(p \wedge \neg p)=$ $\mathrm{T}^{2}(\mathrm{p} \wedge \neg \mathrm{p}) \leftrightarrow \mathrm{T}^{2} \mathrm{p} \wedge \mathrm{F}^{2} \mathrm{p}, \tau(\mathrm{p} \rightarrow \mathrm{q})=\mathrm{T}^{2}(\mathrm{p} \rightarrow \mathrm{q}) \leftrightarrow \mathrm{F}^{2} \mathrm{p} \vee \mathrm{T}^{2} \mathrm{q}$, etc. The counterexample to conditional proof in $\mathrm{L}_{3}-\mathrm{p} \wedge \neg \mathrm{p} \mid==_{3} \mathrm{q}$ but $\mid=/=_{3}(\mathrm{p} \wedge \neg \mathrm{p}) \rightarrow \mathrm{q}-$ fails for the $\mathrm{L}_{3}$-translation of $\mathrm{L}_{2}$ because $\mathrm{Ax}_{\text {Class }} \mid=={ }_{3} \mathrm{~T}^{2}(\mathrm{p} \wedge \neg \mathrm{p}) \rightarrow \mathrm{T}^{2}(\mathrm{q})$.

More generally, we can prove the following translation theorem in complete analogy to theorem (4) of section 3.1:

(15) Theorem $\left(\mathrm{L}_{2}\right.$ into $\left.\mathrm{L}_{3}\right)$ :

(15.1) Every bivalent valuation function $\operatorname{val}_{2}$ over $\wp$ corresponds exactly to a valuation function $\mathrm{val}_{3}$ over $\mathrm{L}_{3 \text {.Class }, \tau}$ that satisfies the axioms $\mathrm{Ax}_{\text {Class }}$ such that for every $\mathscr{D}_{2}$-formula A: 
$\operatorname{val}_{2}(A)=o^{2}$ iff $\operatorname{val}_{3}\left(O^{2}(A)\right)=t$, where $o^{2}=t^{2} / f^{2}$ iff $O^{2}=T^{2} / F^{2}$.

(15.2) $\Gamma \mid=={ }_{\mathrm{L} 2} \mathrm{~A}$ iff $\operatorname{Ax}_{\text {Class }} \cup \mathrm{T}^{2}(\Gamma) \mid==_{\mathrm{L} 3} \mathrm{~T}^{2}(\mathrm{~A})$.

For the sake of the semantic coherence between $\mathrm{L}_{2}$ and $\mathrm{L}_{3}$ we require again two bridge axioms, but now we must be careful. Intuitively the bridge axioms should say that if an atomic sentence $\mathrm{p}$ is trivalently true (resp. false), then it is also bivalently true (resp. false). However, we cannot express the bridge axioms as (i) $p \rightarrow T^{2}(p)$ and (ii) $\neg p \rightarrow F^{2}(p)$ (like we did this in (5) of section 3.2, with $\mathrm{T}=\mathrm{T}^{3}$ instead of $\mathrm{T}^{2}$, and likewise for $\mathrm{F}$ ), because in $\mathrm{L}_{3}, \mathrm{p}$ and $\mathrm{T}^{3}(\mathrm{p})$, are not equivalent. Implications (i) and (ii) would lead to failure when we contrapose (ii), obtaining $\neg \mathrm{F}^{2}(\mathrm{p}) \rightarrow \mathrm{p}$, which together with $\mathrm{T}^{2}(\mathrm{p}) \rightarrow \neg \mathrm{F}^{2}(\mathrm{p})$ would imply (iii) $\mathrm{T}^{2}(\mathrm{p}) \rightarrow \mathrm{p}$; but (iii) and (i) would entail $\mathrm{p} \leftrightarrow \mathrm{T}^{2}(\mathrm{p})$, i.e., the 'collapse' of $\mathrm{L}_{3}$ into $\mathrm{L}_{2}$. Therefore we have to explicate the two bridge axioms as $\left(i^{*}\right) \mathrm{T}^{3}(\mathrm{p}) \rightarrow \mathrm{T}^{2}(\mathrm{p})$ and (ii*) $\mathrm{F}^{3}(\mathrm{p}) \rightarrow \mathrm{F}^{2}(\mathrm{p})$, where $\mathrm{T}^{3}$ and $\mathrm{F}^{3}$ are defined in $\mathrm{L}_{3}$ as explained in sec. 3.1 (we now write $\mathrm{T}^{3}$ and $\mathrm{F}^{3}$ for $\mathrm{T}$ and $\mathrm{F}$ of sec. 3.1, to desambiguate them from $\mathrm{T}^{2}$ and $\mathrm{F}^{2}$ ).

A similar translation of $\mathrm{L}_{2}$ is possible for all n-valued logics that have "truth" as a designated value and within which the operations of n-valued truth and falsity are definable. For many other non-classical logics, however, it is impossible to embed classical logic via translation. There are two possible reasons for the impossibility of such a translation. First, the non-classical logic may be too weak; thus the translation is technically impossible. Second, the translation would be technically possible, but is philosophically inadequate. While the first case applies to paraconsistent and to quantum logic, the second case applies to intuitionistic logic.

For the system LP of paraconsistent logic the translation method fails, because LP's designated values are $\mathrm{T}^{3}$ and $\mathrm{B}^{3}$, and as explained in section 4.1 , it is impossible to define truth-only $\left(T^{3}\right)$ in $L P$. Therefore the axiom $T^{2}(A) \dot{V} F^{2}(A)$ (together with $T^{2}(\neg A) \leftrightarrow F^{2}(A)$ and $\mathrm{F}^{2}(\neg \mathrm{A}) \leftrightarrow \mathrm{F}^{2}(\mathrm{~A})$ ) cannot enforce in $\mathrm{LP}$ that $\mathrm{T}^{2}(\mathrm{~A})$ and $\mathrm{F}^{2}(\mathrm{~A})$ are bivalent (either trueonly or false-only); the designatedness of $\mathrm{T}^{2}(\mathrm{~A}) \dot{\mathrm{V}} \mathrm{F}^{2}(\mathrm{~A})$ is compatible with $\mathrm{T}^{2}(\mathrm{~A})$ and $F^{2}(A)$ having the value $b$. Even stronger, there is no formula $X(p)$ of LP whose designatedness could entail that $\mathrm{p}$ is true-only. Thus the representational power of LP is strictly weaker than $\mathrm{L}_{2}$ or $\mathrm{L}_{3}$. ${ }^{12}$

In intuitionistic logic, the translation of $\mathrm{L}_{2}$ into $\mathrm{L}_{\mathrm{i}}$ could be technically carried out in the same way as for $\mathrm{L}_{3}$, by extending the intuitionistic language $\mathscr{L}_{\mathrm{i}}$ by the bivalent operators $\mathrm{T}^{2}, \mathrm{~F}^{2}$ and adding the axiom set $\mathrm{Ax}_{\text {Class. }}$ The bridge axioms can be expressed as $\mathrm{A} \rightarrow$ $\mathrm{T}^{2}(\mathrm{~A})$ and $\neg \mathrm{A} \rightarrow \mathrm{F}^{2}(\mathrm{~A})$ without entailing collapse (because $\neg \mathrm{A}$ does not entail $\mathrm{A}$ ). Thus the translation is technically possible; however, it is philosophically inadequate. The translation would allow one to derive the bivalence axiom $T^{2}(A) \vee \neg T^{2}(A)$ for $L_{2}$ translations, but $\mathrm{L}_{\mathrm{i}}$ 's assertions are based on the proof view of assertion. According to this view the validity of $T^{2}(A) \vee \neg T^{2}(A)$ in $L_{i}$ means that one can prove this disjunction and thus can prove either $T^{2}(A)$ or $\neg T^{2}(A)$, for every formula $A$. But this is against the spirit of intuitionistic logic which admits propositions whose truth value is not decidable by a constructive proof.

A translation of classical logic into quantum logic QL appears also to be impossible. Indeed, since the implicit semantics of QL is bivalent, the introduction of an intensional truth operation $\mathrm{T}^{2}$ would be pointless, because it would satisfy the correspondence

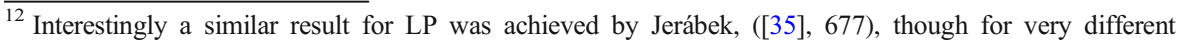
translation functions (recall sec. 3.2.3).
} 
axiom $\mathrm{T}^{2}(\mathrm{~A}) \leftrightarrow \mathrm{A}$. What would be needed is a translation of classical negation and disjunction, $\tau(\neg A)$ and $\tau(A \vee B)$, into QL-formulas that behave like the classical connectives, but such formulas do not exist.

\subsection{Second Objection - the Metalogic of Translation Theorems}

The proof of the translation theorems in sections 3-4 is performed by using a classical metalogic. As mentioned above, not all non-classical logicians allow classical logic in their meta-language. Some non-classical logicians insist on level-coherence and use their non-classical logic also at the meta-level. Such a 'through-and-through' proponent of a non-classical logic could object that the translation theorems have not been proved in the 'right' logic. Does this problem constitute an ultimate circularity within our account? A comprehensive discussion of this question is not possible here. Instead, we confine ourselves to two replies to this challenge: the first reply is a weakness argument and the second is a dialectic refutation strategy.

\subsubsection{The Weakness Argument}

The metalogical proof of the translation theorem in sec. 3.1 uses only very weak logical rules. Since the axioms $\mathrm{Ax}_{\mathrm{Luk}}$ are valid in both $\mathrm{L}_{2}$ and $\mathrm{L}_{3}$, what is needed in the proof of lemma 2 is the rule of replacement of logical equivalents $\Gamma \mid==A \leftrightarrow B /$ $\Gamma \mid==\mathrm{C} \leftrightarrow \mathrm{C}[\mathrm{B} / \mathrm{A}]$ (that holds in $\mathrm{L}_{2}$ and $\mathrm{L}_{3}$ ). Beyond that, the proof uses only finitary set theory and the classical max-rule and min-rule for the designated values of conjunction and disjunction, which hold in all multi-valued logics. Thus the metalogical proof of the translation theorem of section 3.1 should be acceptable in all multi-valued logics. Similar arguments may be applied to other translation theorems.

\subsubsection{The Dialectic Refutation Strategy}

It is not clear whether the weakness argument works for all other translation theorems. For example, certainhyperintensionallogics [42] donotaccepttheruleofreplacingequivalents. So let us assume that the proponent of a non-classical logic $L^{*}$ rejects the metalogical proof of the translation theorem of $\mathrm{L}^{*}$ into classical logic $\mathrm{L}_{2}$. Even if this is the case, we can still apply the following dialectic refutation strategy:

There are two possibilities:

(i) Either $\mathrm{L}_{2}$ is re-translatable into $\mathrm{L}^{*}$ in some way that is acceptable for proponent of $\mathrm{L}^{*}$. In this case the metalogical proof of the translation theorem of $\mathrm{L}^{*}$ into $\mathrm{L}_{2}$ can be translated from the $\mathrm{L}_{2}$-metalogic into the $\mathrm{L}^{*}$-metalogic and the $\mathrm{L}^{*}$-proponent has to accept it.

(ii) Or $\mathrm{L}_{2}$ is not retranslatable into $\mathrm{L}^{*}$ in some way that is acceptable for the proponent of $\mathrm{L}^{*}$. In this case, $\mathrm{L}^{*}$ is not representationally optimal from $\mathrm{L}^{*} \mathrm{~s}$ own point of view, while $L_{2}$ is representationally optimal from $L_{2}$ 's point of view. We argue that such a situation constitutes a reason to prefer $\mathrm{L}_{2}$ over $\mathrm{L}^{*}$, because if one uses the resources of $\mathrm{L}_{2}$, then provably everything that can be expressed and derived in $\mathrm{L}^{*}$ can also be expressed and derived in $\mathrm{L}_{2}$, while this is not so if one uses the resources of $\mathrm{L}^{*}$. 


\subsection{From Optimality to Dominance}

\subsubsection{Global ceteris paribus advantages of classical logics}

In sec. 6.2 we have seen that $\mathrm{L}_{3}$ and some other many-valued logics are intertranslatable with $\mathrm{L}_{2}$. This fact shows that $\mathrm{L}_{2}$ is not the only representationally optimal logic; some other many-valued logics are representationally optimal, too. In this section we argue that the situation is nevertheless not symmetric. Classical logic has two global ceteris paribus advantages as a unifying metalogic:

(i) Determinateness in the metalogic: We are interested in descriptions that are as informative and thus as determinate as possible. Therefore we are interested in constructing logical frameworks whose syntactic and semantic properties are determined. We do not want a notion of proof for which the question of whether a conclusion follows from a premise set is irreducibly indeterminate, nor are we interested in a logical system whose consistency is indeterminate (etc.). This speaks in favor of using not a trivalent, but a classical bivalent logic as metalogic. Should there really arise a situation where we encounter an irreducible indeterminateness, we can express this by using intensional operators.

(ii) Naturalness and induction from practice: It is common practice to discuss the pros and cons of competing logics within a classical metalogic. Likewise it is common practice in mathematical logic to use classical metalogic for the semantics of a non-classical logic. These facts of our practice don't 'prove' anything, and there are exceptions, e.g., constructivist mathematicians using an intuitionistic metalogic. However, these facts seem to confirm the thesis that a classical metalogic is the most natural choice of a framework for the comparison and evaluation of competing systems of logic.

\subsubsection{Local Advantages of Classical and Non-Classical Logics}

A further important ceteris paribus criterion for choice of logics is simplicity (cf. [71]). The simplicity of a logic has many dimensions, concerning the simplicity of its expressions, its proof system, its semantics, as well as the simplicity of the translations by which other logics can be embedded into it. What follows from the simplicity criterion for the choice of a logic? Assume we are in a domain whose description requires the logical operations of a non-classical $\operatorname{logic} \mathrm{L}_{n}$. Then the question is: what is simpler - using $\mathrm{L}_{n}$ directly or using the translation of $\mathrm{L}_{n}$ into $\mathrm{L}_{2 . n}$ ? This depends on the context of application. As a first example, consider quantum logic. The logical representation of linear combinations and orthocomplements of quantum-physical states is simpler in QL than in QL's translation into classical logic ([1], 185). On the other hand, if we want to express that a quantum system is in a pure versus a superposed state, we need in addition the resources of classical logic (recall sec. 5.2), which speaks in favour of using QL's translation into classical logic. As a second example, consider Lukasiewicz' three-valued logic. Assume we have good reasons for thinking that certain propositions describing our domain are undetermined. If there are only a few propositions of this sort and most propositions are adequately described in $\mathrm{L}_{2}$, then using the extended logic $\mathrm{L}_{2 . \mathrm{Luk}}$ is clearly preferable to a complicated 'context-switching' between 
$\mathrm{L}_{3}$ and $\mathrm{L}_{2}$. On the other hand, in a domain where more-or-less all propositions are threevalued (if such a domain exists), the employment of $\mathrm{L}_{3}$ throughout would be simpler than using $\mathrm{L}_{3}$ 's translation in $\mathrm{L}_{2 . \mathrm{Luk}}$.

\subsubsection{Summary of conclusions}

In this paper we have demonstrated that four major systems of non-classical logic - multivalued, intuitionistic, paraconsistent and quantum logics - can be translated into classical logic in a meaning-preserving way, by introducing additional intensional operators into the language. Two major philosophical conclusions were drawn from this result: First, non-classical logics are not incommensurable with classical logic, but can be semantically embedded into it. Second, classical logic is representationally optimal, since if a non-classical logic turns out to have advantages for particular purposes, it can be translated into classical logic. In the last section we investigated the possibility of inverse translations. We have seen that not many, but at least some non-classical logics, e.g. Lukasiewicz' three-valued logic, can be likewise representationally optimal. Despite this fact we have argued that the situation is not symmetric. Classical logic has global ceteris paribus advantages as a unifying metalogic, and (in many but not in all domains) local advantages as a most simple object logic. One may ask: Why didn't we bring in these advantages of classical logic from the start? The reason is that without the intertranslatability argument, the incommensurability problem would prevent that these advantages become justificatorily crucial. A proponent of a non-classical logic $\mathrm{L}^{*}$ could insist that $\mathrm{L}^{*}$ is the correct logic, and correctness is more important than these ceteris paribus advantages. In combination with translatability, however, these advantages may become decisive, because the proponent of $\mathrm{L}^{*}$ can reformulate $\mathrm{L}^{*}$ in the classical framework $\mathrm{L}_{2}$, where (s)he can implement the metaphysics of $\mathrm{L}^{*}$ while enjoying the ceteris paribus advantages of $\mathrm{L}_{2}$.

Acknowledgements For important discussion and help I am indebted to Heinrich Wansing, Diderik Batens, Graham Priest, Manuel Bremer, Hannes Leitgeb, Alexandre Costa-Leite, Jean-Yves Beziau, Corina Strößner and two unknown referees.

Funding Open Access funding enabled and organized by Projekt DEAL. This work was supported by the DFG (Deutsche Forschungsgemeinschaft), research unit FOR 2495.

\section{Declarations}

Conflict of Interest The authors declare that they have no conflict of interest.

Open Access This article is licensed under a Creative Commons Attribution 4.0 International License, which permits use, sharing, adaptation, distribution and reproduction in any medium or format, as long as you give appropriate credit to the original author(s) and the source, provide a link to the Creative Commons licence, and indicate if changes were made. The images or other third party material in this article are included in the article's Creative Commons licence, unless indicated otherwise in a credit line to the material. If material is not included in the article's Creative Commons licence and your intended use is not permitted by statutory regulation or exceeds the permitted use, you will need to obtain permission directly from the copyright holder. To view a copy of this licence, visit http://creativecommons.org/licenses/by/4.0/. 


\section{References}

1. Ashcroft, M. (2010). Does science influence the logic we ought to use: A reflection on the quantum logic controversy. Studia Logica, 95, 183-206.

2. Baltag, A., \& Smets, S. (2005). Complete axiomatizations for quantum actions. International Journal of Theoretical Physics, 44(12), 2267-2282.

3. Baltag, A., \& Smets, S. (2011). Quantum logic as a dynamic logic. Synthese, 179(2), 285-306.

4. Beall, J. C., \& Restall, G. (2006). Logical pluralism. Oxford Univ. Press.

5. Beziau, J.-Y. (1999). A sequent calculus for Lukasiewicz's three-valued logic based on Susko's bivalent semantics. Bulletin of the Section of Logic, 28(2), 89-97.

6. Birkhoff, G., \& von Neumann, J. (1936). The logic of quantum mechanics. Annals of Mathematics, 37, $823-843$.

7. BonJour, L. (1985). The structure of empirical knowledge. Harvard Univ. Press.

8. Bremer, M. (2014). Restall and Beall on logical pluralism: A critique. Erkenntnis, 79, 293-299.

9. Brouwer, L. E. J. (1912). Intuitionism and formalism. Reprinted in Benacerraf \& Putnam (eds.), Philosophy of mathematics: selected readings (pp. 77-89). Cambridge University Press, 2nd ed., 1983.

10. Bueno, O. (2010). Is logic a priori? The Harvard Review of Philosophy, 17, 105-117.

11. Caret, C. R. (2017). The collapse of logical pluralism has been greatly exaggerated. Erkenntnis, 82, 739760.

12. Carnielli, W. A., Coniglio, M. E., \& D'Ottavio, I. M. E. (2009). New dimensions on translations between logics. Logica Universalis, 3, 1-18.

13. Dalla Chiara, M. L., \& Giuntini, R. (2002). Quantum logics. In D. Gabbay \& F. Guenthner (Eds.), Handbook of philosophical logic (Vol. 6, pp. 129-228). Kluwer.

14. Daniel, W. (1989). Axiomatic description of irreversible and reversible evolution of a physical system. Helvetica Physica Acta, 62, 941-968.

15. Dishkant, H. (1972). Semantics of the minimal logic of quantum mechanics. Studia Logica, 30, 17-29.

16. Dummett, M. (1976). Is logic empirical?. Reprinted in M. Dummett, Truth and Other Enigmas (pp. 269289). Harvard University Press, 1978.

17. Dummett, M. (1991). The logical basis of metaphysics. Harvard University Press.

18. Faure, C., Moore, D. J., \& Piron, C. (1995). Determinstic evolution and Schroedinger flows. Helvetica Physica Acta, 68, 150-157.

19. Feldbacher, C. (forthcoming). Epistemic engineering. Rowman \& Littlefield.

20. Field, H. (1996). The aprioricity of logic. Proceedings of the Aristotelian Society, 96, 59-379.

21. Fine, K., \& Schurz, G. (1996). Transfer theorems for multimodal logics. In Copeland, J. (ed.), Logic and reality. Essays on the legacy of Arthur Prior (pp. 169-213). Cambridge Univ. Press.

22. Gardner, M. (1972). Is quantum logic really logic? Philosophy of Science, 38, 508-529.

23. Gödel, K. (1934). Zum intuitionistischen Aussagenkalkül. Anzeiger der Österreichischen Akademie der Wissenschaften, 69, 65-66.

24. Goldblatt, R. (1974). Semantical analysis of orthologic. Journal of Philosophical Logic, 3, 19-35.

25. Goldman, A. (1999). Knowledge in a social world. Oxford Univ. Press.

26. Gottwald, S. (1989). Mehrwertige Logik. Berlin; Akademie-Verlag.

27. Greco, J. (2005). Justification is not internal. In M. Steup \& E. Sosa (Eds.), Contemporary debates in epistemology (pp. 257-270). Blackwell Publishing.

28. Haack, S. (1976). The justification of deduction. Mind, 85(337), 112-119.

29. Hellman, G. (1980): "Quantum Logic and Meaning", PSA 1980 (Proceedings of the Biennial Meeting of the Philosophy of Science Association), 2, 493-511.

30. Henderson, L. (2018). The problem of induction. In Stanford Encyclopedia of Philosophy (Summer 2018 Edition), https://plato.stanford.edu/archives/sum2018/entries/induction-problem/.

31. Hjortland, O. T. (2013). Logical pluralism, meaning-variance, and verbal disputes. Australasian Journal of Philosophy, 91(2), 355-373.

32. Hjortland, O. T. (2017). Anti-exceptionalism about logic. Philosophical Studies, 174, 631-658.

33. Horvath, J., \& Koch, S. (2021). Experimental philosophy and the method of cases. Philosophy Compass, 16, e12716. https://doi.org/10.1111/phc3.12716.

34. Jauch, J. M. (1968). Foundations of quantum mechanics. Addison-Wesley.

35. Jerábek, E. (2012). The ubiquity of conservative translations. Review of Symbolic Logic, 5(4), 666-678.

36. Kleene, S. C. (1952). Metamathematics. North Holland. 
37. Kooi, B., \& Tamminga, A. (2013). Three-valued logics in modal logic. Studia Logica, 101, 1061-1072.

38. Kreisel, G. (1958). Elementary completeness properties of intuitionistic logic with a note on negations of prenex formulas. Journal of Symbolic Logic, 23, 317-330.

39. Kripke, S. A. (1965). Semantical analysis of intuitionistic logic. In J. Crossley \& M. A. E. Dummett (Eds.), Formal systems and recursive functions (pp. 92-130). North-Holland Publishing.

40. Kuhn, T.S. (1962). The structure of scientific revolutions. Univ. of Chicago press (3rd edition 1996).

41. Lehrer, K. (1990). Theory of knowledge. Routledge.

42. Leitgeb, H. (2019). HYPE: A system of hyperintensional logic. Journal of Philosophical Logic, 48, 305-405.

43. Lipton, P. (1991). Inference to the best explanation. Routledge.

44. Łukasiewicz, J. (1920). O logice trojwartosciowej. Ruch Filozoficny, 5, 170-171. Translated in J. Łukasiewicz (1970), Selected works. North-Holland and Warsaw.

45. Malinowski, G. (1993). Many-valued logics. Clarendon Press.

46. McKinsey, J., \& Tarski, A. (1948). Some theorems about the sentential calculi of Lewis and Heyting. Journal of Symbolic Logic, 13, 1-15.

47. Moschovakis, J. (2018). Intuitionistic logic. Stanford Encyclopedia of Philosophy, plato.stanford.edu/ archives/win2018/entries/logic-intuitionistic.

48. Papineau, D. (1993). Philosophical naturalism. B. Blackwell.

49. Popper, K. (1968). Birkhoff and von Neumann's interpretation of quantum Mmechanics. Nature, 219, 682-685.

50. Priest, G. (1979). Logic of paradox. Journal of Philosophical Logic, 8, 219-241.

51. Priest, G. (2006). In Contradiction. Oxford University press ( $2^{\text {nd }}$ edition).

52. Priest, G. (2013). Paraconsistent logic. In Stanford Encyclopedia of Philosophy http://plato.stanford.edu.

53. Psillos, S. (1999). Scientific realism. How science tracks truth. Routledge.

54. Putnam, H. (1968). Is logic empirical? Reprinted as 'The logic of quantum physics' in H. Putnam, Philosophical Papers. Vol. 1 (pp. 174-197 ). Cambridge University Press 1979, $2^{\text {nd }}$ ed.

55. Rautenberg, W. (1979). Klassische und nichtklassische Aussagenlogik. Vieweg.

56. Salmon, W. C. (1957). Should we attempt to justify induction? Philosophical Studies, 8(3), 45-47.

57. Schurz, G. (2006). Alethic modal logic and semantics. In D. Jacquette (ed.), A companion to philosophical logic (pp. 442-477). B. Blackwell, 2nd ed.

58. Schurz, G. (2008). The Meta-inductivist's winning strategy in the prediction game. Philosophy of Science, 75, 278-305.

59. Schurz, G. (2018). Optimality justifications: New foundations for foundation-oriented epistemology. Synthese, 195, 3877-3897.

60. Schurz, G. (2019). Hume's problem solved: The optimality of meta-induction. MIT Press.

61. Schurz, G., \& Hertwig, R. (2019). Cognitive success. Topics in Cognitive Science, 11(1), 7-36.

62. Sellars, W. (1975). The structure of knowledge. In H.-N. Castaneda (Ed.), Action, knowledge, and reality (pp. 295-347). Bobbs-Merrill.

63. Sereni, A., \& Sforza Fogliani, M. P. (2020). How to water a thousand flowers. On the logic of logical pluralism. Inquiry, 63(3-4).

64. Sorensen, R. (2018). Vaguenes. In The Stanford Encyclopedia of Philosophy (Summer 2018 edition), plato.stanford.edu/archives/sum2018/entries/vagueness/.

65. Stachel, J. (1986). Do quanta need a new logic? In R. G. Colodny \& A. Coffa (Eds.), From quarks to quasars: Philosophical problems of modern physics (pp. 229-347). University of Pittsburgh Press.

66. Sterkenburg, T. (2019). The meta-inductive justification of induction. Philosophy of Science, 86, 981-992.

67. Suszko, R. (1977). The Fregean axiom and polish mathematical logic in the 1920's. Studia Logica, 36, 373-380.

68. Van Cleve, J. (1984). Reliability, justification, and induction. In P. A. French, T. E. Uehling, \& H. K. Wettstein (Eds.), Causation and causal theories. Midwest studies in philosophy. Vol. 9 (pp. 555-567). Univ. of Minnesota Press.

69. Van Fraassen, B. (1975). The labyrinth of quantum logics. In C. A. Hooker (Ed.), The logico-algebraic approach to quantum mechanics (pp. 577-607). Reidel.

70. Wansing, H., \& Shramko, Y. (2008). Suszko's thesis, inferential many-valuedness, and the notion of a logical system. Studia Logica, 88, 405-429.

71. Williamson, T. (2017). Semantic paradoxes and abductive methodology. In B. Armour-Garb (Ed.), Reflections on the liar (pp. 325-346). Oxford University Press.

72. Woodruff, P. M. (1970). Logic and truth value gaps. In K. Lambert (Ed.), Philosophical problems in logic (pp. 121-142). Reidel. 
73. Woods, J. (2019). Against reflective equilibrium for logical theorizing. Australasian Journal of Logic, 16(7), 319-341.

74. Wright, C. (2004). Warrant for nothing (and foundations for free)? Aristotelean Society Supplementary, $78(1), 167-212$.

Publisher's Note Springer Nature remains neutral with regard to jurisdictional claims in published maps and institutional affiliations. 